\title{
Infrared studies of the surface acidity of oxides and zeolites using adsorbed probe molecules
}

\author{
Johannes A. Lercher ${ }^{*}$, Christian Gründling, Gabriele Eder-Mirth \\ University of Twente, Department of Chemical Technology, P.O. Box 217, 7500 AE Enschede, Netherlands
}

\begin{abstract}
The use of infrared spectroscopy to probe the surface acidity of oxides and molecular sieves is reviewed. The experimental requirements and the type and nature of probe molecules available are also discussed. Special emphasis is given to the criteria that have to be met to arrive at a characterization of the solid that is useful for its catalytic application.
\end{abstract}

Keywords: Infrared spectroscopy; Surface acidity; Oxides; Zeolites

\section{Introduction}

Solid acids are widely used in the chemical and petrochemical industry as catalysts and sorbents. The extent of their use is rapidly increasing, because many liquid acid catalysts need to be replaced with environmentally more compatible chemicals. This widespread range of utilization has spurred interest in describing their chemical and structural properties with sufficient detail and accuracy to be able to relate them to the catalytic properties, primarily for a rational basis of further catalyst and process development. Thus, characterization of such materials with respect to their acid-base properties, i.e., the assessment of the strength, the concentration and the nature of acid sites is an

\footnotetext{
* Corresponding author.
}

integral part of catalyst development programs. Infrared spectroscopy always played an important role in such characterizations, as it permits direct monitoring of the interaction between sorbed molecules and the catalysts. It is, therefore, not too surprising that excellent books [1-4] and reviews [5-12] exist on this topic, some of which are rather recent $[13,14]$.

Providing a complete compilation of suitable probe molecules and examples is, thus, not attempted. What is tried, however, is to summarize the most important conclusions of these papers and to indicate the principal advantages and, especially, the limitations of using probe molecules for acidity characterization, i.e., the use of a yardstick that has quite different properties than the molecules that are to be catalytically converted. Specific examples will be given to show that acid-base properties are not abstract properties that can be fully assessed by a multitude of probe molecules, but that the acid- 
ity and basicity themselves change with the reactant. This makes it necessary to probe the surface or intra-pore chemistry with molecules similar to the reacting molecules, better with the reactants itself.

The reason why this is so important lies in the nature of the solid acid. Any acid and, thus, also a solid acid, is only defined with respect to a base and the medium in which it is used. Two consequences follow from that: (i) Acidity cannot be assessed by investigations of the solid alone, but must be probed by interaction of a (base) molecule with the solid surface. (ii) The medium in which the interaction is probed and, thus, the surrounding molecules might influence the solid surface. The characterization must therefore always be adapted to the targeted use of the solid acid. Consequently, any characterization reveals only a particular behavior of the solid towards the molecules used.

We will try to account for these aspects and, thus, first give an overview of the acid-base sites on solid surfaces, followed by a review of techniques applicable to obtain IR spectra of solid acids in contact with potential probe molecules to characterize them. Finally, two examples of the limitations of this approach will be given. It will be shown, why characterizing the solids by means of their interaction with the reactants is more appropriate than with probe molecules, if the goal is to relate acid-base with sorptive or catalytic properties.

\section{Acid sites of macroporous oxides and molecular sieves}

Acid and base sites on the surface of an oxide are the direct consequence of the termination of the bulk and the exposure of metal cations (Lewis acid sites) or oxygen atoms (Lewis/Brønsted base sites). Alternatively, the surface free energy may be reduced by terminating surface planes with hydroxyl groups. It is interesting to note, however, that the partial exposure of metal cations on perfect apolar low index surface planes does not necessarily lead to the generation of Lewis acid sites. McKay and Henrich [15] showed in a series of elegant experiments that the apolar $\langle 100\rangle$ surface of $\mathrm{NiO}$ (which contains $\mathrm{Ni}$ and $\mathrm{O}$ atoms in stoichiometric amounts) does not sorb polar molecules such as water. Upon ion bombardment, however, defect sites are generated on the surface which then readily sorb water and other polar compounds. For an extensive treatment of that problem the reader is referred to the works of Zecchina et al. [16,17], who discussed the role of various coordinatively unsaturated sites and their role for sorption and catalysis on $\mathrm{MgO}$. The important message from these studies is that the surface chemistry of real oxides (with high specific surface areas) will be dominated by surface defects. As these defects are metastable, their concentration and nature might change drastically under reaction conditions or after admittance of the probe molecule itself.

\subsection{Single oxides}

For oxides containing only one type of metal cation, Brønsted and Lewis sites might be expected on the surface depending upon the difference in the ionic radius between the metal cation and oxygen and upon the reducibility of the oxide. The concentration of hydroxyl groups (Brønsted acid sites) which are generated by dissociative adsorption of water will depend strongly on the preparation conditions and the thermal treatment of the oxide. Usually, these hydroxyl groups are weakly to moderately acidic and form weak hydrogen bonds with sorbed molecules [18-20]. As a simple guideline to estimate the acid strength one could propose that a hydroxyl group will be the more acidic, the more covalent the bulk metal-oxygen bond is $[21,22]$. Generally, it is to be expected that for a given oxide the concentration of Lewis and Brønsted acid sites will increase with increasing specific surface area, because the concentration of defects per surface area will increase. For a given specific surface area, an increase in acid 
site concentration is expected with increasing radius of the metal cation and with increasing reducibility of the oxide. This is due to the increase in accessibility of metal cations with increasing radius (e.g., the $\mathrm{Si}^{4+}$ cation is not accessible in silicates because of its small radius and the tetrahedral coordination with four oxygens).

At this point another complicating factor should be mentioned. Hydrogen bonding, donor-acceptor type bonding, and even ionic bonding will depend largely on the geometric match of the orbitals involved. In the terminology introduced by Pearson [23] this means that a non polarizable group (hard donor, hard base) will preferentially interact with an already polarized surface group, while a polarizable group (soft donor, soft base) will interact more strongly with a polarizable sorption site on the surface (i.e., a rather covalent functional group or a large transition metal cation).

\subsection{Mixed oxides}

In addition to the factors that lead to the generation of acid sites on the surfaces of single oxides, the presence of cations with differing valencies must lead to oxygen vacancies next to the lower valent cation or to the generation of Brønsted acidic hydroxyl groups for charge compensation [24-27]. While the bulk properties of the mixed oxides will be largely determined by the equilibration of the electronegativity of the elements involved [21,22], the strength of the acid sites may change dramatically as the accessibility of the different Lewis acid sites changes (e.g., the larger and lower valent $\mathrm{Mg}^{2+}$ cations in silica-magnesia mixed oxides lead to a sudden appearance of relatively strong Lewis acid sites, when small amounts of magnesia are added to silica [28]). The substitution of lower valent metal cations in, e.g., silicates and phosphates, also leads to the generation of strong Brønsted acid sites as outlined below for the microporous molecular sieves [29].

\subsection{Molecular sieves}

In contrast to the oxides discussed above, molecular sieves have most of their acid sites located within the microporous crystal structure and not at the surface terminating the individual crystallites. Thus, the acid sites are an integral part of the molecular sieve structure. The best examples are zeolites, where the incorporation of $\mathrm{Al}^{3+}$ in a silica matrix requires the addition of a proton or a metal cation in order to balance the charge [29]. Lewis acid sites may occur because of several reasons: (i) Heating may lead to partial disintegration of the zeolite lattice and the formation of sub-nanoscale metal oxide particles within the channels of the microporous material [30]. (ii) The exchangeable metal cations affiliated with the tetrahedrally coordinated aluminum act as Lewis acid sites [31]. (iii) Larger and, hence, accessible di- or trivalent metal cations, e.g., $\mathrm{Co}, \mathrm{Mg}, \mathrm{Cr}$, are incorporated in the lattice [32]. (iv) Reversible hydrolysis of metal-oxygen bonds allows access of polar molecules to the metal cations [33].

\section{Experimental techniques}

Because IR spectroscopy is a regularly used technique for catalyst characterization, compilations and reviews on the various experimental techniques are numerous [1-14,34]. Transmission-absorption, diffuse reflectance [34,35], attenuated total reflection $[4,36,37]$, specular reflectance [38], and photoacoustic spectroscopy [39-41] are among the most frequently used techniques. The principal information obtained with all these techniques is equivalent and personal choices may be dominated by the local availability and the experimental necessities such as sample particle size [4] and the molecular extinction coefficient of the sample. Recently, the possibilities to decrease the sampled volume were greatly improved by the availability of FTIR microscopy (or micro FTIR spec- 
troscopy), which allows the sample cross section (of catalyst samples) to be reduced to about $20 \times 20 \mu \mathrm{m}$ with a sensitivity equivalent to standard transmission-absorption spectroscopy (usually requiring samples covering cross sections of at least one $\mathrm{cm}^{2}$ ) [42].

The vast majority of experiments are currently performed in the transmission-absorption and the diffuse reflectance mode. Typical examples of IR cells to be used for sorption and reaction studies in transmission-absorption mode were designed for high vacuum experiments [43-45], carrier gas experiments [46-48], and IR microscopy (Fig. 1) [49,50]. All these designs have in common that the sample handling including activation, sorption, reaction, and temperature programmed desorption can be performed in situ. In most cases, the temperature of the sample in contact with the sorbed or reacting molecules can be chosen in a way that the determination of thermodynamic parameters of the sorption is possible, but it is not frequently realized in practice. This is in most cases due to ill defined conditions within the IR cell (e.g., because of severe limitations with respect to mass and heat transport).

Two experimental details might greatly enhance the value of the experiments. First, the sorbate has to be introduced to the catalyst sample in sufficiently small quantities so that a gradual increase of the coverage with the sorbate can be achieved. If the experiment aims to assess the acid sites with respect to their strength, it is important that the adsorption/desorption equilibrium is established at any point of the measurement. Otherwise parallel sorption on all sites that are able to irreversibly interact with the sorbate will occur. This would lead to the appearance of a rather homogeneous acid site distribution even for cases where acid sites of very different strengths exist [51]. A good example for this phenomenon is the sorption of ammonia at ambient temperature, as ammonia will sorb on all Brønsted acidic hydroxyl groups irrespective of their acid strength at any reasonable experimental partial pressure. If the admission of doses of sorbate does not hinder subsequent adsorption, the method, however, could be potentially used to titrate the acid sites from the outside to the inside of a catalyst particle (given a homogeneous concentration of the base molecule exists in the reactor). Indications for this are given by Deeba and Hall [52] for alkylamine titration in liquid media.

The second important experimental detail is that a good mixing of the sorbate within the cell takes place and/or that the change in partial pressure of the sorbate is rapid with respect to the uptake by the catalyst. In this way, the time dependence of the uptake can be used to estimate the diffusion coefficient at a given equilibrium pressure (constant pressure type experiments provided) and temperature. Such experiments have been reported for vacuum [53], car-

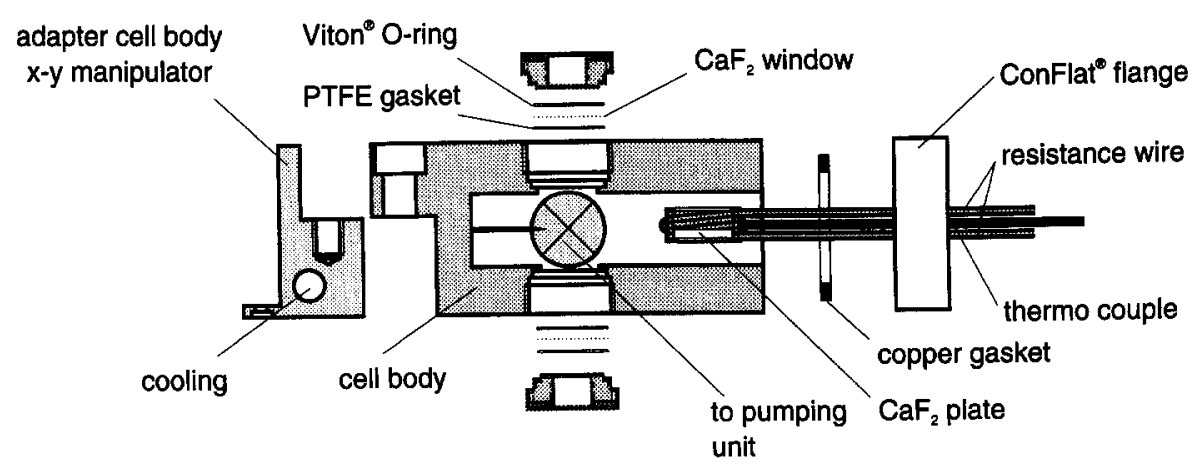

Fig. 1. Schematic representation of a cell for in situ IR microscopy experiments. 


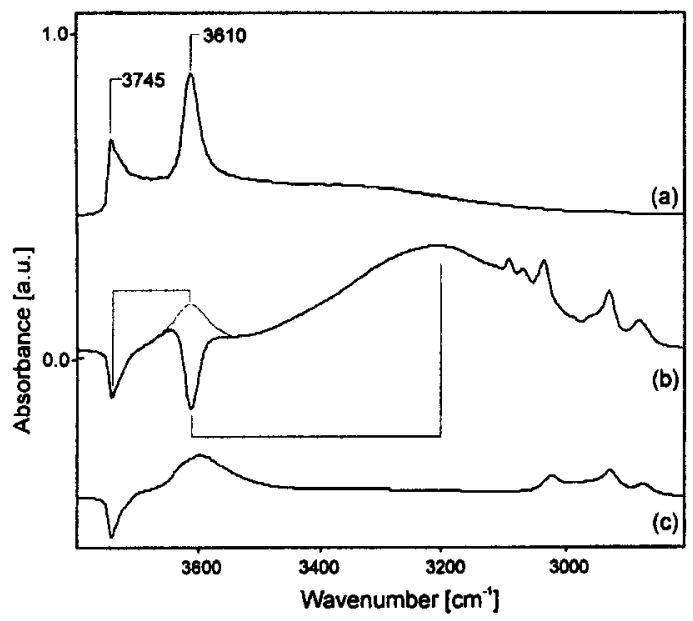

Fig. 2. IR spectrum of activated HZSM5 (a) and the difference between the IR spectra after adsorption of 1 mbar toluene (b) and 1 mbar 1,3,5 trimethylbenzene (c) and the activated zeolite at 308 $\mathrm{K}$

rier gas [54,55] and even infrared microscopy $[50,56]$ providing unique information on molecular aspects of the transport in catalyst pores.

\section{IR spectroscopy of free Brønsted acid sites}

Hardly any property of a solid acid catalyst has been studied so frequently as the nature and concentration of the functional (hydroxyl) groups on oxides and zeolites (e.g., [18,28,5762]). The origin of these hydroxyl groups may be (i) the relaxation of the terminating lattice by dissociative sorption of water or (ii) the balancing of charges arising from substitution of lattice cations with cations of different valency. An example is given in Fig. 2 that shows the transmission-absorption IR spectrum of the zeolite HZSM5. The band at $3745 \mathrm{~cm}^{-1}$ is attributed to the stretching vibration of the terminal $\mathrm{SiOH}$ groups either being located at the boundaries of the zeolite crystal or at the surface of non-crystalline material $[63,64]$. The band at $3610 \mathrm{~cm}^{-1}$ is due to the stretching vibration of the bridging hydroxyl groups affiliated with the tetrahedrally coordinated alu- minum [65]. The difference in the width at half height of these bands may be affiliated with the non-uniformity of the hydroxyl groups and/or the anharmonicity of the $\mathrm{OH}$ vibration.

On first sight, it is tempting to relate the position of the free hydroxyl group to its acid strength. In these lines of argumentation the force constant of the $\mathrm{OH}$ vibration is usually assumed to be directly proportional to the depth of the potential well of the anharmonic oscillator, i.e., that a stronger $\mathrm{O}-\mathrm{H}$ bond is related to a larger force constant. Let us discuss briefly why this is fundamentally incorrect.

The wavenumber of IR bands due to fundamental vibrations between 4000 and $1000 \mathrm{~cm}^{-1}$ is determined by the transition from the vibrational ground level $\left(\nu_{0}\right)$ to its first excited state $\left(\nu_{1}\right)$. For the approximation of the harmonic oscillator, the energy of this transition is proportional to the square root of the force constant $(k)$ and inversely proportional to the square root of the reduced mass $(\mu)$. The force constant is proportional to the second derivative of the potential with respect to $x$, the displacement from equilibrium. It is equivalent to the curvature of the potential at the minimum position and only empirical correlations relate this curvature to the well depth of the anharmonic oscillator, which determines the energy needed to cleave the $\mathrm{O}-\mathrm{H}$ bond homolytically. However, for closely related homologues, such as substituted carboxylic acids, good correlations between their acid strength and the wavenumber of the $\mathrm{O}-\mathrm{H}$ stretching vibrational band exist.

The wavenumber of the $\nu_{\mathrm{OH}}$ of the hydroxyl group on oxides, however, might be more related to the type of hydroxyl group than to its acid strength. In this context, it should be emphasized that the hydroxyl groups on silica and on magnesia show the same wavenumber (3745 $\mathrm{cm}^{-1}$ ) [20], but the acid strength of the hydroxyl groups on silica is much higher than that of magnesia. On the other hand, Jacobs and Mortier [60,66,67] reported a linear correlation between the $\nu_{\mathrm{OH}}$ of the Brønsted acidic $\mathrm{OH}$ group in various zeolites and the overall elec- 
tronegativity indicating that correlations between the chemical composition of zeolites, the wavenumber and the acid strength can be expected for such bridging hydroxyl groups.

In line with the previous statement that an acid is best defined with respect to a particular base, the hydrogen bonding between a donor molecule and a free hydroxyl group provides a means of assessing the strength of the $\mathrm{OH}$ bond. The hydrogen bonding between the hydroxyl group and a basic (electron-pair donor [68]) molecule broadens the potential curve of the $\mathrm{O}-\mathrm{H}$ oscillator and, thus, shifts the band to a lower wavenumber. For a given donor molecule, the magnitude of the shift increases with increasing acid strength of the hydroxyl group. For a given kind of hydroxyl group the wavenumber difference between the perturbed and the unperturbed $\mathrm{OH}$ band increases with increasing base strength of the donor molecule $[18,20]$. A typical example of such a change in the IR spectrum after contacting the free hydroxyl groups of a solid with probe molecules can be seen in Fig. 2. It shows the IR spectrum of HZSM5 (in the spectral region of the hydroxyl groups) after evacuation at $773 \mathrm{~K}$ for one hour and the IR spectra of the sample equilibrated with toluene and 1,3,5-trimethylbenzene. Under the chosen conditions ( $p=1 \mathrm{mbar}, T=$ $308 \mathrm{~K})$, toluene rapidly enters the pores of the molecular sieve, while 1,3,5-trimethylbenzene diffuses so slowly that within the time scale of the experiment it can be considered as incapable of entering the molecular sieve pore system.

Two types of information can be extracted from the observations. The first is that toluene (at sufficiently high partial pressures) interacts with both hydroxyl groups, while 1,3,5-trimethylbenzene interacts only with the terminal $\mathrm{SiOH}$ groups. This indicates that the $\mathrm{SiOH}$ groups are mainly located outside the zeolite crystallites or on extrazeolite material and that there are no steric constraints to reach them. In contrast, the $\mathrm{OH}$ groups affiliated with the tetrahedrally coordinated aluminum are not accessible for 1,3,5trimethylbenzene under the experimental condi- tions chosen and, therefore, are concluded to be located predominately in the zeolite pores.

The second observation relates to the fact that the $\mathrm{OH}$ band shift of the $\mathrm{SiOH}$ groups upon adsorption of toluene is significantly smaller than the corresponding shift of the SiOHAl groups (bridging hydroxyl groups) indicating that the interaction of toluene with these latter sites is much stronger and, hence, their acid strength is by far higher.

\section{IR spectroscopy of probe molecules and their interaction with oxides and zeolites}

\subsection{Criteria for selection}

As the type of probe molecule chosen will influence the obtained characteristics of the probed solid and, hence, will also affect the structure-activity relationship derived, the choice of the appropriate probe molecule is very important. While it is the opinion of the authors that ultimately the reactants should be used as probe molecules, when possible, practical criteria to select probe molecules will be discussed below. These criteria combine the earlier suggestions of Knözinger [14] and Paukshtis and Yurchenko [10]. Subsequently, a short description of the spectroscopic characteristics of the individual molecules will be given. Specific examples of the sorption of basic probe molecules on selected oxides/molecular sieves will then be used to point out the potential and the shortcomings of the most commonly used probes in relation to general sorptive or catalytic properties.

In all cases, the quantitative determination of the concentration of sorbed molecules is seen crucial for the appropriate interpretation of the IR spectra. The adsorption stoichiometry of probe molecules per sorption site can be determined (i) spectroscopically from the disappearance or the perturbation of the functional groups of the solid acid (e.g., hydroxyl groups) and the 
increase of characteristic bands of the sorbed molecules or (ii) by parallel gravimetric or volumetric measurements. The known stoichiometry is mandatory to avoid misinterpretations due to chemical molecule-molecule interactions (leading to the formation of larger clusters interacting with one particular site) and also due to spectroscopic phenomena such as dipole-dipole coupling.

The most important criteria are summarized below. Conceptual selection criteria are compiled in Table 1, which is adopted from Paukshtis and Yurchenko [10].

\subsubsection{Criterion: The probe molecule should} have dominating base and rather weak acidic properties

Upon sorption, the molecule should primarily interact with its base (electron pair donor [68]) function, while the acidic (electron pair acceptor) function should hardly interact with the solid. Molecules thought to fulfil these requirements ideally are ammonia and most amines including pyridine. Taking ammonia as an example, it was argued that the primary interaction on acidic surfaces takes place between its nitrogen atom (via the electron lone pair) and the Brønsted or Lewis acid (electron pair acceptor) site on the surface. Recent theoretical calculations for ammonia sorption on protonic zeolites [69], however, indicate that the interaction between the hydrogens of ammonia and the oxygens of the oxidic lattice contribute markedly to the stabilization of the formed sorption complex. Thus, the acid strength of the hydroxyl group is not the only parameter determining the strength of interaction in the sorption complex (i.e., whether or not ammonia is protonated upon sorption). This should be taken as indication that more complex molecules which are frequently used as probes for acidity (e.g., ketones [70,71]) might have even more pronounced simultaneous acid and base interactions which makes it difficult to determine the acid properties of the solid unambiguously.

\subsubsection{Criterion: The IR spectrum of the sorbed} probe molecule should allow to distinguish between sorption on protonic (Brønsted) and aprotic (Lewis) acid sites

This is possible, when significant differences in the IR spectrum of the Brønsted and Lewis bound molecule exist (e.g., for ammonia and pyridine $[1,72])$ or when changes in the IR

Table 1

Conceptional criteria for the selection of probe molecules to characterize solid acids

\begin{tabular}{|c|c|c|c|}
\hline \multirow[b]{2}{*}{ Sorption complex } & \multirow{2}{*}{$\begin{array}{l}\text { Lewis acid site } \\
\text { Electron pair donor acceptor }\end{array}$} & \multicolumn{2}{|c|}{ Brønsted acid site } \\
\hline & & Hydrogen bond & Ion pair (hydrogen bonded) \\
\hline Detection of complex formation & $\begin{array}{l}\text { Change in the wavenumber of the } \\
\text { absorption maximum of } \nu_{B}\end{array}$ & $\begin{array}{l}\text { Change in shape and } \\
\text { absorption maximum of } \nu_{\mathrm{OH}}\end{array}$ & $\begin{array}{l}\text { Disappearance of the catalysts } \nu_{\mathrm{OH}} \text {. } \\
\text { Appearance of } \nu_{\mathrm{D}-\mathrm{H}}^{+} \text {and /or } \delta_{\mathrm{B}-\mathrm{H}}^{+}\end{array}$ \\
\hline $\begin{array}{l}\text { Most exact methods of acid } \\
\text { strength determination }\end{array}$ & $\begin{array}{l}\text { Correlations between the changes } \\
\text { in } \nu_{\mathrm{B}} \text { and the heat of adsorption }\end{array}$ & $\begin{array}{l}\text { Shifts of } \nu_{\mathrm{OH}} \text { for a given } \\
\text { probe molecule }\end{array}$ & $\begin{array}{l}\text { Thermal stability of the hydrogen } \\
\text { bonded ipc }\end{array}$ \\
\hline $\begin{array}{l}\text { Determination of concentration } \\
\text { of acid sites }\end{array}$ & From the intensity of $\nu_{B}$ & From the intensity of $\nu_{\mathrm{OH}}$ & $\begin{array}{l}\text { From the intensity of characteristic } \\
\text { bands of the ipc }\end{array}$ \\
\hline Required spectral properties & $\begin{array}{l}\text { Shift of } \nu_{B} \text { must be significant } \\
\text { compared to its half width }\end{array}$ & $\begin{array}{l}\text { Absence of } \mathrm{OH} \text { groups in } \\
\text { the probe molecule }\end{array}$ & $\begin{array}{l}\text { The characteristic band has to be } \\
\text { unequivocally attributed to the ipc }\end{array}$ \\
\hline Frequently used molecules & $\begin{array}{l}\text { Pyridine, ammonia, acetonitrile, } \\
\text { benzonitrile, } \mathrm{CO}\end{array}$ & $\begin{array}{l}\text { Benzene, acetone, pyridine, } \\
\text { substituted pyridines, } \\
\text { amines, acetonitrile }\end{array}$ & $\begin{array}{l}\text { Ammonia, pyridine and its } \\
\text { derivatives }\end{array}$ \\
\hline
\end{tabular}

$\nu_{\mathrm{B}}=$ Characteristic vibration of the probe molecule B. $\nu_{\mathrm{OH}}=\mathrm{OH}$ stretching vibration of the catalyst. ipc $=$ Ion pair complex. 
spectrum of the solid upon sorption of the probe molecule are characteristic for protonation or coordinative bonding. The latter applies for hydroxyl groups and their disappearance or the shift in the absorption maxima of their IR bands upon sorption of the probe molecule can also be used to determine the accessibility.

Only based on spectroscopic results, it is difficult to decide whether the molecule sorbed on the hydroxyl group is protonated. In case of strong bases like ammonia, protonation is strongly indicated, by both theoretical calculations [69,73] and vibrational spectroscopy [5]. For weaker bases such as alcohols, ketones and water, this is more difficult to decide. Experimental results were interpreted in terms of hydrogen bonding [74-76] protonation [77-80] and equilibria between hydrogen bonded and protonated forms $[81,82]$, while recent ab initio theoretical calculations suggest that protonation of these moderately strong bases does not take place on strong Brønsted acid sites of zeolites [73,83].

Differentiation between coordinative sorption on hydroxyl groups and on coordinatively unsaturated metal cations has to involve monitoring of the bands of the oxide (zeolite) hydroxyl groups and testing the thermal stability of the formed electron pair donor-acceptor complex. Sorption on coordinatively unsaturated metal cations is usually stronger than sorption on hydroxyl groups [15].

\subsubsection{Criterion: The probe molecule should} allow to differentiate between acid sites of the same type, but of different strength

This requires that the IR spectra of the molecule sorbed on sites with different acid strength show detectable differences. Usually, a strong base such as pyridine is better suited to differentiate between subtle differences in acid strength as long as it is not protonated, while a weak base (e.g., benzene $[60,84]$ ) will be more suitable to differentiate between sites with large differences in strength. However, when inter- preting the interaction between the acid site and the base probe molecule not only their acid-base strengths, but also the polarizability of the orbitals [85] involved in the acid-base bonding has to be taken into account. A general treatment of that concept was given by Pearson [23] and early applied by Burwell et al. [86,87] for a qualitative description of sorbate-sorptive interactions. In general, the concept predicts that interaction between acid-base sites of comparable polarizability are the most favorable ones (meaning that hard-hard and soft-soft interactions are preferred to hard-soft interactions). The less polarizable an orbital is, the harder it is according to the Hard-Soft-Acid-Base (HSAB) concept [23]. Thus, protons of hydroxyl groups or $\mathrm{Li}^{+}$cations are rather hard acid sites, while, e.g., $\mathrm{Cs}^{+}$or transition metal cations are considered as soft acid sites. Similarly, the nitrogen in amines has to be seen as a rather hard base site, while the nitrogen in a nitrile group (e.g., in acetonitrile) or the carbon atom in $\mathrm{CO}$ are rather polarizable and, thus, soft base sites. Therefore, it is at least necessary to choose a probe molecule of similar hardness as the reactant to realistically probe the acid-base properties with respect to a particular reactant. Note that the attribution and the ranking of the hardness of molecules are frequently controversial $[10,14]$

\subsubsection{Criterion: The size of the probe molecule should be comparable to the size of the reactant to probe the concentration of acid sites relevant for a particular reaction}

The smallest probe molecules that are frequently used are ammonia and $\mathrm{CO}$ (minimum kinetic diameter $k_{\mathrm{NH} 3}=0.165 \mathrm{~nm}$ and $k_{\mathrm{CO}}=$ $0.073 \mathrm{~nm}$ ). Both molecules will probe the maximum concentration of acid sites that might play a role in a catalyzed reaction. As the size of the molecule increases, fewer acid sites can be reached. Thus, the steric constraints around the acid sites might be probed by selecting a series of probe molecules with increasing size or steric constraints around the electron pair donor (base) 
function. While this is a feasible approach to determine constraints around Lewis acid sites, care must be taken with Brønsted acid sites. It could be shown that the protons of hydroxyl groups can be attracted by the base molecule from sites which are sterically well shielded. This imposes a special problem for the determination of the accessibility of sites in zeolites, where interactions of strong bases with hydroxyl groups in virtually inaccessible locations have been observed. This is apparently achieved by a large charge separation [14]. Similar phenomena have not been observed with macroporous oxides. Knözinger [14] also emphasizes the possibility of lateral blocking of nearby acid sites by large base molecules.

\subsection{Spectral properties of probe molecules}

The most important characteristics and applications of frequently used probe molecules will be briefly outlined below. Generally, the gas phase proton affinity was found a very valuable measure to compare their base strength $[51,88]$. While this approach neglects the multiple interaction of the base molecule with the solid acid, it seems nevertheless better suited to give a first estimate of the to-be-expected intensity of the acid-base interaction than $\mathrm{p} K_{\mathrm{a}}$ values obtained from the liquid phase. This is due to the fact that certainly on the surfaces of oxides (and maybe even in the pores of zeolites), the polarizing effect of the environment is much lower than in the liquid state, although a liquid like environment has been suggested to exist in the pores of zeolites $[89,90]$.

\subsection{Ammonia}

Ammonia is probably the most frequently used probe molecule for acidity assessment. Its small size allows to probe quantitatively almost all acid sites in micro, meso- and macroporous oxides. Qualitative differences between various samples in respect to acid strength cannot be inferred from the IR spectra for Brønsted acid sites and only with great care for Lewis acid sites. In terms of the Pearson HSAB principle, it constitutes a relatively hard base and is, thus, expected to strongly interact with hard acid sites, such as protons of hydroxyl groups or small metal cations. The protonated (ammonium ion) molecule and the coordinatively bound ammonia can be differentiated spectroscopically by their $\mathrm{NH}$ deformation and stretching vibrations. The ammonium ion shows absorptions at 1450 and $3300 \mathrm{~cm}^{-1}$, coordinatively bound ammonia at 1250,1630 and $3330 \mathrm{~cm}^{-1}$. The deformation vibrations at 1450 and $1630 \mathrm{~cm}^{-1}$ are used as most reliable indicators for the presence of protonated and coordinatively bound ammonia, respectively. The spectral region of the $\mathrm{NH}$ stretching vibrations is relatively complex, because the distortion of the molecule upon adsorption leads to a multitude of bands of free and perturbed $\mathrm{N}-\mathrm{H}$ vibrations which further overlap with several bands of overtones and combination vibrations of the deformation modes [1].

Two major complications, however, arise when ammonia is used as probe molecule. One complication relates to investigations at elevated temperature $(T>500 \mathrm{~K})$, when $\mathrm{NH}_{3}$ tends to sorb dissociatively forming $\mathrm{NH}_{2}$ or $\mathrm{NH}$ groups on Lewis acid sites or replacing existing $\mathrm{OH}$ groups with $\mathrm{NH}_{2}$ groups [91,92]. For oxides, like $\mathrm{TiO}_{2}, \mathrm{MoO}_{3}$, and $\mathrm{WO}_{3}$, this may even lead to nitride formation [93]. The other complication relates to the presence of molecular water, in which case the generation of ammonium ions on acidic oxides like silica-alumina may be enhanced [5]. Furthermore, spectroscopic detection would be problematic as several IR bands of water and ammonia would overlap. It is, therefore, important to remove water carefully before investigations.

\subsection{Aliphatic amines}

Alkylamines are stronger bases than ammonia and, therefore, like ammonia better suited 
for the determination of the overall concentration of Brønsted and/or Lewis acid sites than for the differentiation of the acid strength. In general, it is possible to distinguish unequivocally between sorbed protonated and non-protonated amines by means of their IR spectra.

The most frequently used molecule is $n$ butylamine. Lewis bound $\mathrm{n}$-butylamine gives rise to a characteristic band at $1605 \mathrm{~cm}^{-1}\left(-\mathrm{NH}_{2}\right.$ deformation band) on oxides. Protonated butylamine is observed upon sorption on silicaalumina and zeolites [94] and is characterized by IR bands at 1590 and $1510 \mathrm{~cm}^{-1}$.

Surface reactions of aliphatic amines at elevated temperatures have been reported and it does not seem possible to desorb large concentrations of these amines intact from oxide surfaces $[95,96]$. Increase in temperature leads to a Hoffmann type elimination resulting in the desorption of alkenes and ammonia and/or lower substituted amines $[42,97,98]$. On the contrary, this is an elegant parallel experiment to determine the concentration of strong Brønsted and Lewis acid sites, because only Brønsted acid sites quantitatively decompose alkylamines, (with the exception of methylamine) while intact desorption from (weaker) Lewis acid sites has been reported [99].

Trialkylamines might also be considered as probe molecules, because they show only in the protonated form the characteristic $\mathrm{N}-\mathrm{H}$ stretching at approximately $3250 \mathrm{~cm}^{-1}$. However, these molecules disproportionate upon sorption on Brønsted acidic catalysts even at room temperature by generating tetraalkylammonium ions and lower substituted alkylamines. Furthermore, the large kinetic diameter of trisubstituted alkylamines might cause problems affiliated with the accessibility of acid sites in, e.g., small pore zeolites and due to constraints imposed by pore filling in zeolites with a high concentration of acid sites. Since the kinetic diameter of aliphatic amines can be varied by choosing different alkyl groups, the accessibility of acid sites can be probed by selecting a series of amines with increasing size $[95,96,100]$.

\subsection{Pyridine and substituted pyridines}

The $\mathrm{p} K_{\mathrm{a}}$ value of pyridine derived from liquid phase measurements suggests that it is a weaker base than ammonia. Gas phase basicities, however, show that pyridine is a stronger base and, indeed, the ease of protonation and the thermal stability of protonated form are higher than for ammonia [51]. The absorption maxima of some ring vibrations of pyridine are highly sensitive with respect to the form of coordination of pyridine. Using the nomenclature of Kline and Turkevich [101], the bands responding most sensitively to changes in the nature and strength of acid sites correspond to the $19 \mathrm{a}, \mathrm{b}$ and $8 \mathrm{a}, \mathrm{b}$ vibrations. The bands of the $\mathrm{NH}$ stretching vibrations of the pyridinium ion are strongly perturbed by resonance with the overtones of the ring vibrations, which leads to a very complex spectrum.

In most instances, the band around 1540 $\mathrm{cm}^{-1}$ is assumed to be characteristic for pyridinium ions [72], while bands between 1445 and $1460 \mathrm{~cm}^{-1}$ are attributed to coordinatively adsorbed pyridine. While the band at $1540 \mathrm{~cm}^{-1}$ does not change in wavenumber upon varying the acidity of the solid, the band typical for coordinatively bound pyridine increases in wavenumber as the strength of interaction increases. In general, it can be stated that coordinatively unsaturated metal cations in tetrahedral coordination show a stronger interaction with pyridine than the same metal cation in octahedral coordination [102]. For a given coordination, the strength of interaction increases with the ratio between the formal charge and the radius of the cation [102]. Only with rather weakly acidic (usually terminal) hydroxyl groups pyridine binds via hydrogen bonding [109]. This results in rather intense broad bands of the perturbed hydroxyl groups which are shifted to lower wavenumbers (typically to values around $3000 \mathrm{~cm}^{-1}$ and lower) in comparison with the bands of the unperturbed $\mathrm{OH}$ groups upon interaction with pyridine. A good example of the quantitative analysis of pyridine sorption 
was reported by Lavalley and co-workers $[103,104]$ characterizing the strength and concentration of acid sites in partially dealuminated zeolites.

Alkyl substitution of pyridine in the 2- and 6-position enhances the base strength, but induces steric constraints in coordination to acid sites, as the electron lone pair of the nitrogen atom are shielded by the alkyl groups. This makes it very difficult to achieve the optimum sorption geometry necessary for strong bonding to Lewis acid sites, especially to those located on low index surface planes. Sorption of the bulky probe molecule on the more exposed and also mobile hydroxyl groups seems easier. Thus, it was suggested [105] to use 2,6-dimethylpyridine as a specific probe molecule for Brønsted acid sites. This has been challenged by Knözinger and Stolz [106] who demonstrated that 2,4,6-trimethylpyridine is able to interact with $\mathrm{Al}^{3+}$ cations, although the interactions were weaker than those observed with pyridine, which could displace 2,4,6-trimethylpyridine quantitatively. Attempts to use the more bulky 2,6-di-tert-butylpyridine as specific probe for Brønsted acid sites were also not successful [107]. The main sorbate-sorptive interaction occurs via the aromatic ring and not via the electron lone pair of the nitrogen atom which does not allow to discriminate sorption on the Brønsted and Lewis acid sites.

In summary, pyridine and to a lesser extent also substituted pyridines are excellent probe molecules which allow to differentiate between Brønsted and Lewis acid sites and to rank the strength and coordination of Lewis acid sites.

Recently, an interesting proposal has been made to use the NH stretching vibration of protonated pyridine to probe the strength of the corresponding solid base after protonation of pyridine [108]. The results published indicate that once the pyridinium ion is formed, the strength of the corresponding base determines the intensity of the sorbate-sorptive interaction and, hence, the wavenumber of the $\mathrm{N}-\mathrm{H}$ stretching vibration (see Fig. 3 after [120]).

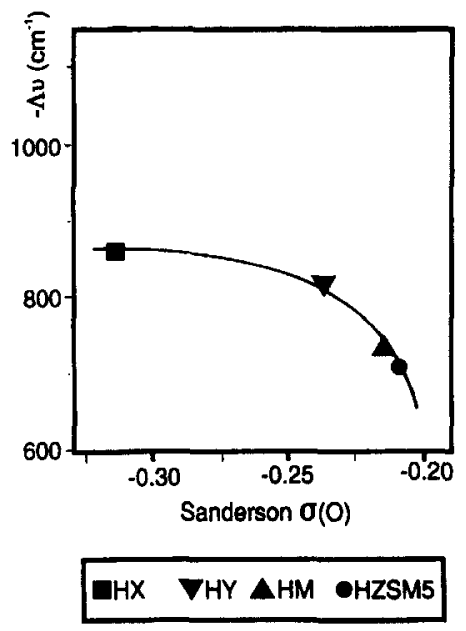

Fig. 3. Dependence of wavenumber shifts $(\Delta \nu(\mathrm{NH}))$ of $\mathrm{PyH}^{+} \ldots{ }^{-} \mathrm{O}$ complex upon the charges of lattice oxygens calculated according to Sanderson's electronegativity (after [120])

\subsection{Nitriles}

Nitriles are relatively weak bases and coordinate via the nitrogen of the nitrile group to the acid sites. Upon interaction, the band of the $\mathrm{CN}$ stretching vibration is shifted to higher wavenumbers. Coordination to accessible metal cations results in blue shifts of approximately $30-60 \mathrm{~cm}^{-1}$ [109], while upon coordination to a hydroxyl group shifts of approximately 10 to $30 \mathrm{~cm}^{-1}$ are found. [110-112].

Because of its small size, acetonitrile is frequently used and successfully applied for the characterization of a large number of oxides [28,113-119]. Problems might arise, however, with respect to the interpretation of the IR spectra of the sorbed species as the $\mathrm{C}-\mathrm{N}$ stretching mode ( $\nu_{2}$ mode) is in Fermi resonance with the $\left(\nu_{3}+\nu_{4}\right)$ combination mode. By using perdeuterated acetonitrile this problem can be overcome [109].

Using a combination of ab initio calculations and IR spectroscopy under carefully controlled conditions, Pelmenshikov et al. [75,76] and Kubelkova and co-workers $[111,112,120]$ conclude that acetonitrile is hydrogen bonded in a neutral complex, even on zeolites with rather 
strong acid sites. The shift of the band of the $\mathrm{OH}$ stretching frequency of the solid increases with increasing positive charge at the bridging hydroxyl groups of the zeolite [120]. Typical IR spectra of sorbed acetonitrile on various zeolites and the dependence of the $\mathrm{OH}$ band shift are depicted in Fig. 4a and b (see Ref. [120]). For phosphate based molecular sieves (e.g., CoAPO5, MgAPO5) acetonitrile sorption seems to indicate primarily interaction with Lewis acid sites [121], although Brønsted acid sites are to be expected with these molecular sieves. It is difficult to judge at this moment whether or not this is due to a surface chemical reaction.

The relatively high reactivity of acetonitrile, especially on basic surfaces poses a serious problem. Careful testing whether or not surface reactions occur are strongly recommended before using acetonitrile for characterizing moderately acidic oxides [109]. The use of larger nitriles, which are less reactive than acetonitrile (e.g., tert-butyronitrile) has been reported to be successful for the characterization of alumina [109], silica-titania and other mixed oxides $[117,122,123]$.

\subsection{Benzene and substituted benzenes}

Benzene and substituted benzenes are weakly basic molecules which form $\pi$-bonds to Brønsted and Lewis acid sites. The strength of these bonds can either be followed via monitoring the shift of the $\mathrm{OH}$ band of the Brønsted acidic hydroxyl groups or via monitoring the changes in the absorption maxima of the bands attributed to the $\mathrm{CH}$ stretching and ring vibrational bands $[60,124]$.

Due to its low base strength, benzene is especially suited to characterize $\mathrm{OH}$ groups with large differences in acid strength. As with any other hydrogen bonding interaction, the extent of the shift is taken as a measure for the acid strength of a particular $\mathrm{OH}$ group [18]. This has led to a ranking in the strength of the hydroxyl groups of oxides in the sequence $\mathrm{B}-\mathrm{OH}<$ $\mathrm{Si}-\mathrm{OH}<\mathrm{Ge}-\mathrm{OH}<\mathrm{P}-\mathrm{OH}$ [125]. For amorphous $\mathrm{SiO}_{2} / \mathrm{Al}_{2} \mathrm{O}_{3}$ which shows only one $\mathrm{OH}$ stretching vibration band around $3750 \mathrm{~cm}^{-1}$, two perturbed $\mathrm{OH}$ bands were observed, shifted by 110 and $310 \mathrm{~cm}^{-1}$, respectively [115]. This indicates the presence of two types of acid sites (a)

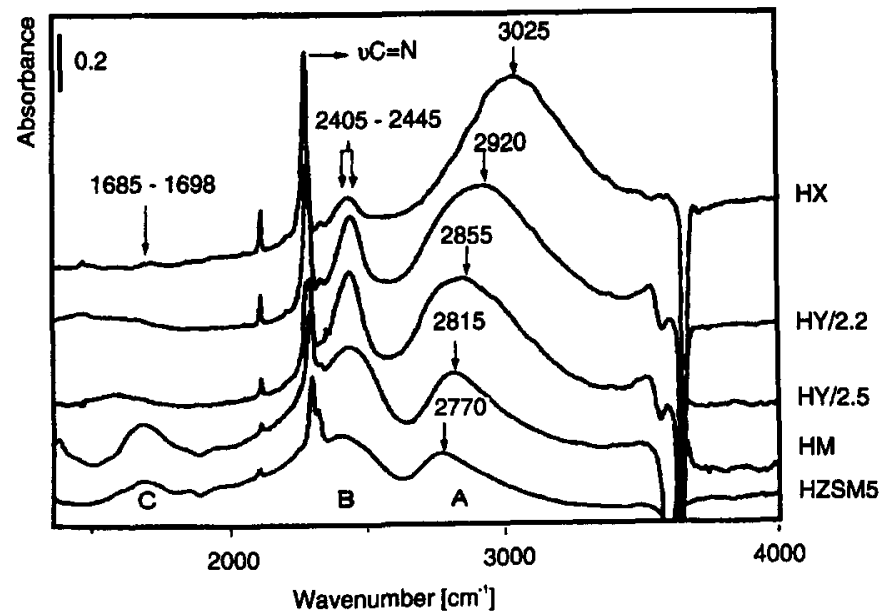

(b)

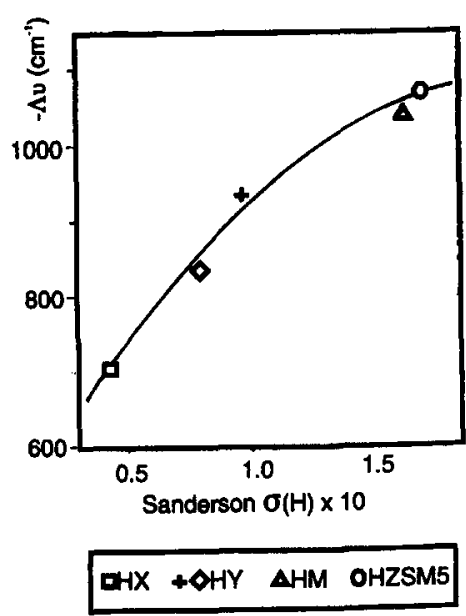

Fig. 4. Differences between the IR spectra of the zeolite after adsorption of $\mathrm{CD}_{3} \mathrm{CN}$ and activated zeolite samples $(0.5<\Theta(\mathrm{OH})<0.65)$ (a) and the dependence of the wavenumber shifts $(\Delta \nu(\mathrm{OH}))$ of the $\mathrm{CD}_{3} \mathrm{CN}$...HO(zeo.) complex on the charges of hydrogen in the bridging hydroxyl groups calculated according to Sanderson's electronegativity (after [120]) (b) 
markedly differing in strength, but giving rise to only one absorption band in the unperturbed state. The weaker acidic sites (corresponding to the smaller shift) are attributed to $\mathrm{SiOH}$ groups, the other hydroxyl groups (stronger acid sites, larger shift) are concluded to be affiliated with protons balancing the substitution of $\mathrm{Al}^{3+}$ for $\mathrm{Si}^{4+}$. Similarly, Jacobs et al. [84] and Jentys and Lercher [124] used benzene adsorption to characterize the heterogeneity of acid sites in faujasite and ZSM5, respectively. It must be mentioned, however, that it may be misleading to use the shift of the hydroxyl group upon benzene adsorption as the only means of acid strength assessment when different materials are compared. Bands of $\mathrm{OH}$ groups in phosphatebased molecular sieves seem to produce a larger red shift upon benzene adsorption than bands of $\mathrm{OH}$ groups of silicate-based materials with similar acid strength [33]. Cloverite and several MeAPO5 samples show shifts of the $\mathrm{OH}$ bands upon interaction with benzene similar to HZSM5, although by means of catalytic evaluation the phosphates can best be classified as relatively weak acids [126-128], while HZSM5 is a rather strong solid acid.

In general, the interaction of benzene with Lewis acid sites is stronger than with Brønsted acid sites [129]. This stems from the fact that in contrast to the asymmetric bonding of the proton to the aromatic ring, the larger metal cations can interact symmetrically with all delocalized electrons in the aromatic ring which enhances the strength of the interaction. Large shifts in the absorption maxima of the $\mathrm{CH}$ stretching vibrations occur upon sorption of benzene and toluene on alkali cations exchanged faujasites with the extent of the shift being proportional to the size of the cation [130]. In the presence of lattice oxygens of high base strength pronounced interactions occur also with the alkyl groups attached to the aromatic ring, shifting the corresponding $\mathrm{C}-\mathrm{H}$ stretching vibration bands to lower wavenumbers [131].

Substituted benzenes can be used to probe steric constraints around acid sites and the loca- tion of acid sites in molecular sieves. A demonstration is given in Fig. 2. using the IR spectrum of toluene and 1,3,5-trimethylbenzene on HZSM5 as discussed in the chapter on IR spectroscopy of free hydroxyl groups. Hydroxyl groups that cannot be reached by the substituted benzenes will remain unperturbed and, providing the molar extinction coefficients are known, the fraction of accessible hydroxyl groups can be determined.

\subsection{Carbon monoxide}

Like benzene, carbon monoxide is a weakly basic molecule with a pronounced soft character. Because of this weak basicity, the interactions with hard solid acids are usually very weak. Thus, low temperature sorption experiments are necessary for more quantitative studies. Under these conditions, $\mathrm{CO}$ is unreactive for all practical purposes. Brønsted and Lewis sites can be qualitatively and quantitatively investigated. The small size of $\mathrm{CO}$ allows to probe nearly all acid sites.

$\mathrm{CO}$ interacts by bonding via the carbon atom to the acid sites which usually shifts the absorption maximum of the $\mathrm{CO}$ stretching vibration band to higher wavenumbers. The interaction involves the (non-bonding) $5 \sigma$ orbital of $\mathrm{CO}$ which donates electrons to the metal or cation and forms a bond with prevailing $\sigma$ character. If a sufficiently high density of the $d$ states exists, electrons from the metal are donated back to the lowest antibonding orbital (i.e., $\left.2 \pi^{*}\right)$. This weakens the $\mathrm{CO}$ bond and lowers the wavenumber of the absorption maximum of the CO stretching vibration $[14,132]$. If the density of d-states is too low or does not exist the $\sigma$ type interaction prevails. The donative bond causes a strengthening of the $\mathrm{CO}$ bond and a blue shift of its IR band. The blue shift increases with increasing strength of electron donation from the $\mathrm{CO}$ molecule to the acid site. For a given type of site (nature of the acid site, hardness) the shift usually increases with in- 
creasing positive charge at the acid site [133139]. This is well supported by theoretical calculations which suggest that the $\mathrm{CO}$ stretching frequency increases monotonously with the electric field strength of the cation [132]. It also increases for a given charge with the softness of the metal cation/Brønsted acid site.

It has to be considered, however, that $\mathrm{CO}$ is sensitive to dipole-dipole interactions which lead to a shift of $\mathrm{CO}$ band to higher wavenumbers with increasing concentration [140]. This problem can be overcome by measuring with increasingly dilute concentrations of $\mathrm{CO}$ $[137,138]$ or by using $\mathrm{CO}$ isotope mixtures in which the two components are systematically changed in concentration [132,141].

Successful examples of the use of $\mathrm{CO}$ for the characterization of oxides and zeolites include studies on alumina, $\mathrm{MgO}, \mathrm{TiO}_{2}, \mathrm{Cr}_{2} \mathrm{O}_{3}, \mathrm{SiO}_{2}-$ $\mathrm{Al}_{2} \mathrm{O}_{3}, \mathrm{~V}_{2} \mathrm{O}_{5}-\mathrm{TiO}_{2}$ and $\mathrm{SiO}_{2}-\mathrm{TiO}_{2}[61,142-$ 147]. The examples show that it is not only possible to assess the charge of an accessible metal cation, but also its coordination on the surface. Lower coordination (e.g., tetrahedral in contrast to octahedral) leads to stronger interaction with $\mathrm{CO}$ which was demonstrated by Knözinger and co-workers [137,138] for transition aluminas with fourfold and sixfold coordination of $\mathrm{Al}^{3+}$ in the bulk. A band at 2190 $\mathrm{cm}^{-1}$ was attributed to $\mathrm{CO}$ coordinated to accessible $\mathrm{Al}^{3+}$ in octahedral positions, while $\mathrm{CO}$ bands above $2200 \mathrm{~cm}^{-1}$ are associated with $\mathrm{CO}$ bound to $\mathrm{Al}^{3+}$ in tetrahedral positions $[137,138,148,149]$.

$\mathrm{CO}$ interacting with hydroxyl groups of oxides and zeolites shows a lower perturbation, but in this case the shift of the hydroxyl group can be used to gain additional information on the strength of the acid site. Successful studies have been reported for oxides by Ghiotti et al. [150], Beebe et al. [151] and Knözinger [152]. For zeolites, the red shift of the $\mathrm{OH}$ stretching vibration band were larger than those obtained by interaction with benzene. Shifts of up to 340 $\mathrm{cm}^{-1}$ were reported $[14,153]$ suggesting that one has to use caution in comparing the strength of interaction with the results obtained with other probe molecules.

\subsection{Less frequently used probe molecules}

Several other molecules such as ketones $[70,71,81,82,154,155]$, aldehydes $[156,157]$, ethers [122,158], alkanes [159] and alkenes $[160,161]$ have also been used as probe molecules.

The most prominent example from the above mentioned molecules concerns the use of ketones (acetone). Acetone is a relatively weak base interacts with acid sites via the electron lone pairs at the oxygen atom of the carbonyl group. Upon sorption, the wavenumber of the carbonyl group shifts to lower wavenumbers the stronger the Lewis or Brønsted acid site is. Despite earlier interpretations [81,82], a consensus seems to have been reached that acetone is not protonated after adsorption on strong Brønsted acid solids [111], but rather forms a neutral hydrogen bonded complex. Such a hydrogen bonded complex involves primarily the electron pair donor function of acetone and can be used to scale the acid strength of $\mathrm{OH}$ groups in mixed oxides [20]. Upon interaction with Lewis acid sites, frequently the electron pair acceptor function of acetone also participates in the bonding. This may lead to surface reactions which impede the general applicability of acetone as a probe molecule. Examples for the use of acetone are given in Refs. [70,71,113]. As discussed for the nitriles, larger ketones show diminished tendency to surface reactions [162]. Aldehydes and ethers are relatively reactive on acidic surfaces [6]. While this reactivity per se is another possibility to compare the acidity of various oxides, the extent and the importance of these surface reactions are often difficult to assess. Thus, it is recommended to use such molecules only if they are reactants in a particular catalyzed reaction. A general description of the sorption structures of the less frequently used probe molecules can be found in Refs. $[1,2]$. 


\section{Quantitative evaluation of acidity}

\subsection{The strength of acid sites}

\subsubsection{Brønsted acid sites}

As outlined above, the wavenumber of the stretching vibration of the free hydroxyl group should not be taken as a measure of its acid strength. The acid strength of Brønsted acidic hydroxyl groups, or more precisely their polarizability, is best measured by using basic probe molecules that remain non-protonated upon adsorption. Using the analogy to well-established correlations between the shift of the $\mathrm{OH}$ stretching frequencies and the enthalpy of formation of the hydrogen bond complex between a donor and an acceptor molecule in liquid phase [163] the magnitude of this shift can be used to scale the acid strength of a hydroxyl group. The shift of the $\mathrm{OH}$ stretching band depends upon the acid strength of the $\mathrm{OH}$ group and the proton affinity (or $\mathrm{p} K_{\mathrm{a}}$ ) of the sorbed molecule. Paukshtis and Yurchenko reported a non linear increase of the shift of the $\mathrm{OH}$ stretching band with increasing proton affinity [10] of the sorbate for $\mathrm{SiO}_{2}$ and $\mathrm{HNaY}$ zeolite. Weakly basic molecules like $\mathrm{CO}$ and (substituted) benzenes, but also ethene, acetonitrile and acetone (which are certainly not protonated upon sorption) were successfully used as probe molecules. Linear correlations between the acid strength of hydroxyl groups for various oxides and the shift of the hydroxyl groups were reported for benzene [60], acetone [20], CO [164,165], and recently also for ethene [164,165] (Fig. 5). Most quantitative descriptions address the mathematical interpretations of these observed interdependencies. A compilation of these attempts is given by Paukshtis and Yurchenko [10].

\subsubsection{Lewis acid sites}

The strength of Lewis acid sites is best determined by monitoring vibrations of sorbed molecules, which are characteristic of the strength of interaction. These are, for example, the ring vibrations of pyridine or the $\mathrm{CO}$ and

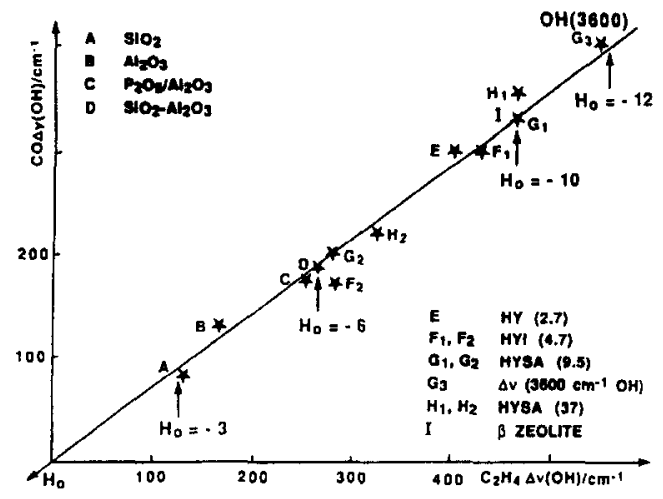

Fig. 5. Interdependence of the wavenumber shifts $(\Delta \nu(\mathrm{OH}))$ of the $\mathrm{CO} \ldots \mathrm{HO}$ complex and the $\mathrm{C}_{2} \mathrm{H}_{4} \ldots \mathrm{HO}$ complex on various solid acids (after [164])

$\mathrm{CN}$ stretching vibration of $\mathrm{CO}$ and acetonitrile, respectively. Benzene is problematic to use for probing the strength of Lewis acids, because the interaction with the benzene ring will encompass the electron pair acceptor strength of the cation and the geometric match between the ring $\pi$-electron system and the cation. A good example for this is the increasing strength of interaction of benzene with increasing size of the alkali cation in ZSM5 [166], although the Lewis acid strength of the cation decreases with its size when probed with other basic molecules as $\mathrm{CO}$ [14] or light alcohols [167].

For a given oxide, the strength of the Lewis acid site depends upon the coordination and formal charge of the cation. The latter can be probed elegantly with the use of small probe molecules like CO $[137,138,148,149]$. The different coordination of one type of cations (e.g., $\mathrm{Al}^{3+}$ in tetrahedral and octahedral coordination) can be clearly differentiated by the use of $\mathrm{CO}$ and also pyridine [102,168]. However, the experimentally determined strength of interaction with Lewis acid sites is also critically dependent upon their local accessibility for a particular base molecule. Thus, great care has to be taken in interpreting the perturbations of larger probe molecules (i.e., pyridine) quantitatively in the absence of other structural data, because variation in the accessibility of the acid sites (which might be perfectly identical in strength) as it is 
frequently the case for molecular sieves might appear as apparent heterogeneity of the acid sites.

\subsection{The concentration of acid sites}

After having established that several probe molecules are well suited to differentiate between sorption on Brønsted and Lewis acid sites, the key problem for the quantitative determination of acid sites lies in the assessment of the molar extinction coefficient. Most emphasis in this respect has been given to ammonia and pyridine (mainly for assessment of the concentration of Brønsted and Lewis acid sites) and to $\mathrm{CO}$ (for the concentration of transition metal cations).

Several factors complicate the analysis: (i) The molar extinction coefficient depends upon the perturbation of the molecule and is therefore related to the local coordination. A specific example is given for $\eta$-alumina by Morterra et al. [168] who emphasized that the extinction coefficient of any adsorbed species is not transferable from one system to another, even when similar chemical and spectroscopic characteristics prevail. (ii) For some molecules (e.g., CO) dipole-dipole coupling may influence intensities and wavenumbers in a complex way. This may pose a problem at high concentrations of acid sites or when the molecules tend to form clusters on the surface [132]. (iii) The temperature influences strongly the molar extinction coefficients (especially for aromatic molecules). This is clearly seen with the sorption of methyl substituted benzenes [169]. It is, thus, necessary to derive the molar extinction coefficients for each temperature investigated. (iv) Care has to be taken that the particle size (diffuse scattering) does not influence the results when several

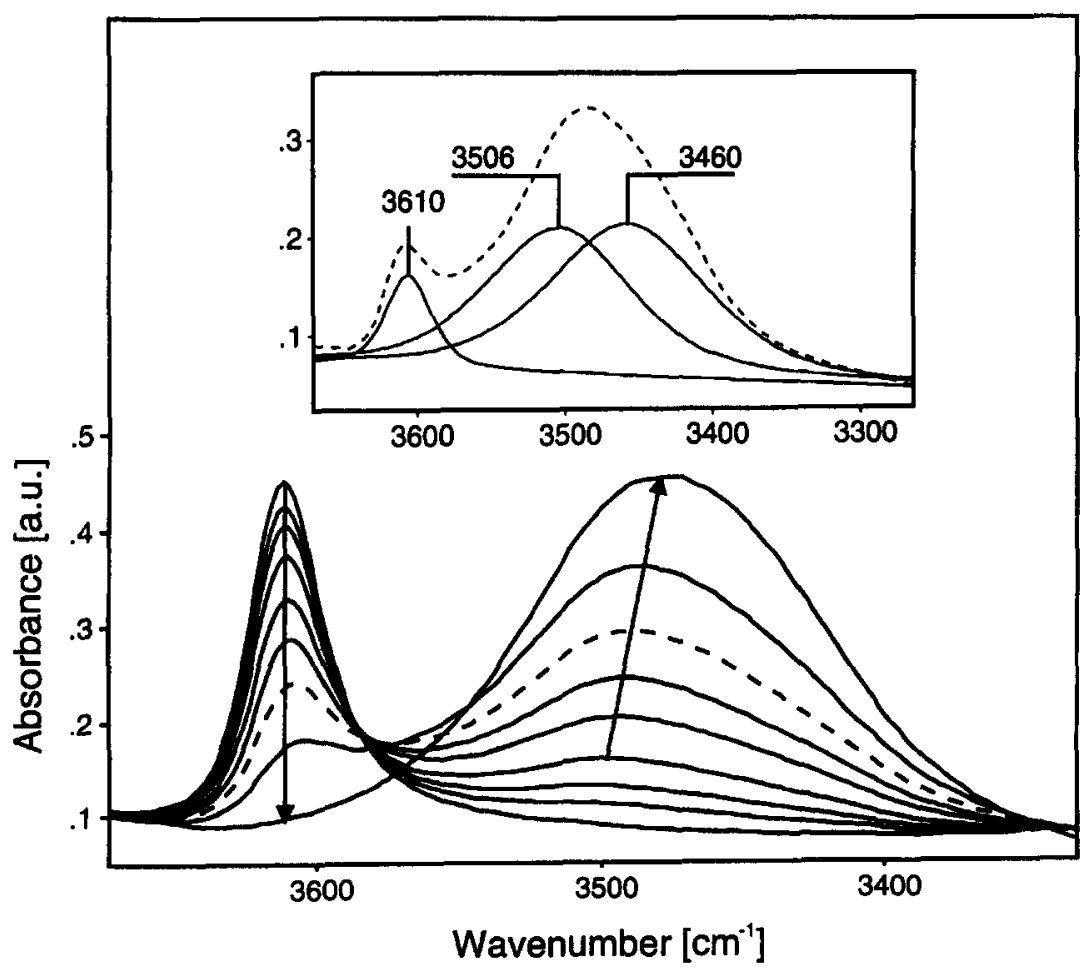

Fig. 6. IR spectra recorded during the adsorption of n-pentane on HZSM5 at $333 \mathrm{~K}$. The arrows indicate increasing equilibrium pressures $\left(10^{-3}-1\right.$ mbar $)$ 
catalysts with widely differing particle size are compared. The use of internal standards (e.g., inert oxides) is strongly recommended.

\section{Limitations in using probe molecules}

So far the possibilities of using the IR spectra of basic molecules interacting with the acid sites of oxides and molecular sieves to characterize acidity have been discussed. Now, two practical examples will demonstrate specific problems encountered in the analysis of acidity. It is the intention to show that probe molecules can be used to estimate the acid-base properties of oxide or molecular sieve catalysts, but that this knowledge is insufficient to understand the details of the reactant-acid site interactions that are necessary to model reactions at a microscopic level. For this purpose, sorption of the reactants is the best option. If this is impossible, the second best solution is to use a probe molecule of similar shape, polarizability, and base strength as the reactant.

\subsection{Alkane sorption in zeolites}

Acidic zeolites such as ZSM5, mordenite and faujasite (H-ZSM5, H-MOR and H-FAU) are frequently used catalysts and catalyst components for sorption and conversion of hydrocarbons. A detailed and unequivocal description of the nature, strength and concentration of the acid sites is indispensable for rational catalyst development. Important questions to address include: (i) Can the hydrocarbons reach all the acid sites? (ii) What is the distribution of the strength of acid sites? (iii) How does the strength of hydrocarbon sorption on various zeolites compare with the strength of sorption of fre-

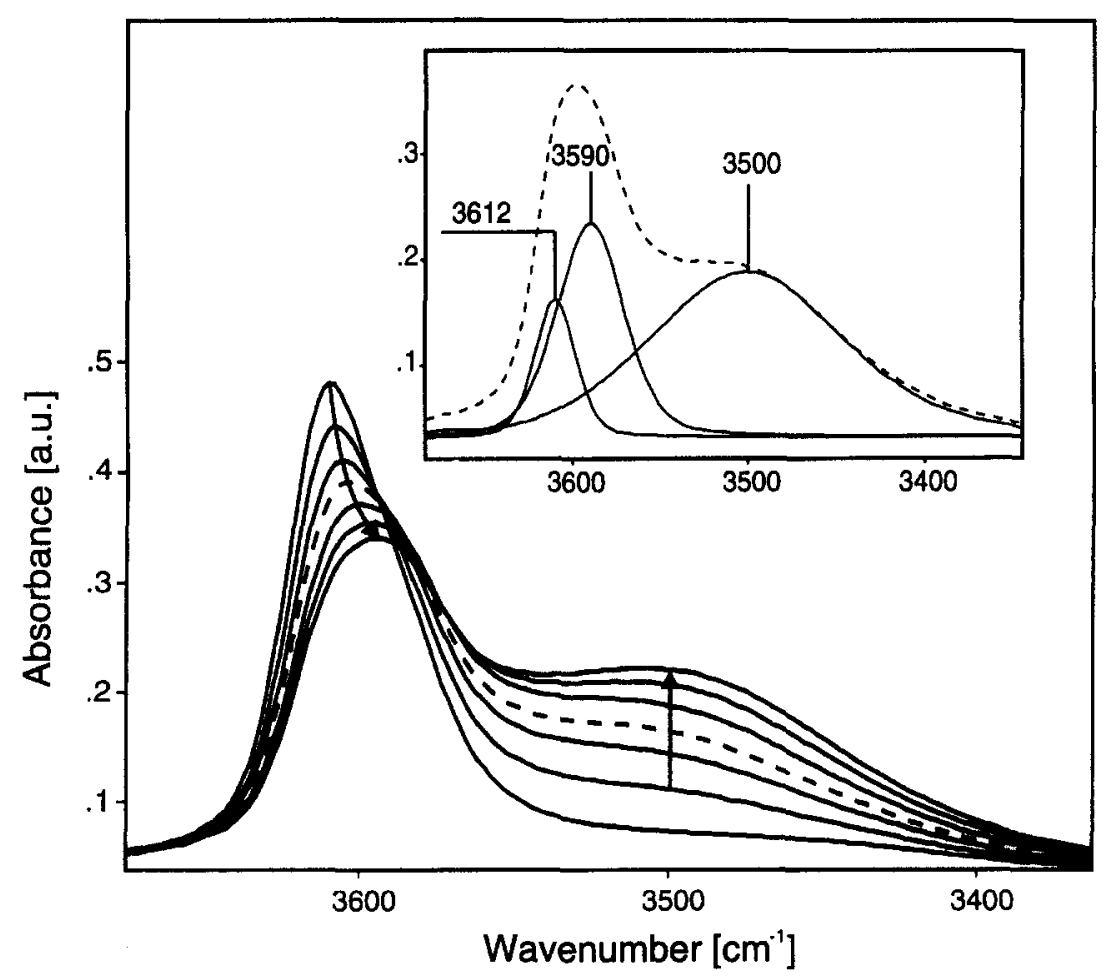

Fig. 7. IR spectra recorded during the adsorption of $n$-hexane on HMOR at $303 \mathrm{~K}$. The arrows indicate increasing equilibrium pressures $\left(10^{-3}-3 \mathrm{mbar}\right)$ 
quently used strong bases like ammonia or pyridine? To address these questions, infrared spectroscopy in combination with gravimetry and calorimetry was used [170]. All three zeolites contain predominantly Brønsted acid sites and rather few Lewis acid sites, as seen by IR spectra of adsorbed ammonia and pyridine.

The disappearance of the IR band characteristic for the hydroxyl groups upon ammonia sorption indicates that ammonia interacts with all acid sites of H-ZSM5 and HMOR. IR spectra indicate that all Brønsted acid sites in H-ZSM5 (Fig. 6) are accessible for alkanes, but only $40 \%$ of these sites in H-MOR (Fig. 7). The fraction of the $\mathrm{OH}$ groups on $\mathrm{H}-\mathrm{MOR}$ that is unable to sorb the alkanes is, nevertheless, slightly perturbed by the alkanes (see minor shift of the band of the SiOHAl groups at $3590 \mathrm{~cm}^{-1}$ in the presence of higher concentrations of alkanes). These results indicate that a (surprisingly large) fraction of acid sites is localized in the side pockets of the mordenite channels and does not seem to take part in catalytic reactions. The reason the access to these sites is limited for alkanes becomes clear after considering the physical dimensions of the side pockets. They have a diameter of $0.39 \times 0.57 \mathrm{~nm}$, substantially smaller than the aperture of the large pores $(0.67 \times 0.7 \mathrm{~nm})$. While the kinetic diameter of linear alkanes is approximately $0.45 \mathrm{~nm}$, the methyl group is smaller and therefore the end of the molecule should be able to reach the acid site. As interactions are not observed this indicates that the alkanes must primarily interact with the $\mathrm{C}-\mathrm{H}$ groups at secondary carbon atoms.

However, the differences in the accessibility of sites upon sorption of pyridine and n-alkanes (only $20 \%$ of the acid sites are inaccessible for pyridine compared to $60 \%$ for alkanes) suggest that arguments based only on the molecule size may also be misleading. Pyridine is apparently able to either deform the zeolite in a way that it is allowed to enter the side pockets or it attracts protons from a somewhat remote location to form the pyridinium ions.

For evaluation of kinetic results this suggests that at ambient temperature only sites interacting with alkanes contribute to sorption and, hence, to catalysis. The open question, however, remains whether or not at reaction temperature the other acid sites are also available for reactants. It should only be noted that a similar situation exists also for H-FAU where only $\mathrm{OH}$ groups in the supercages are able to interact with the alkanes, while a much larger fraction was seen to interact with ammonia and pyridine [171].

The evaluation of the strength of the interaction is more subtle to address, but again IR spectroscopy of the actual reactant/sorbate offers key information required to understand the crucial factors for the interaction with the zeolite lattice.The hydrocarbons form hydrogen bonds of rather uniform strength on HMOR (and also on HFAU) as seen by the symmetric band of perturbed $\mathrm{OH}$ vibrations at $3500 \mathrm{~cm}^{-1}$. On HZSM5, the band of the hydrogen bonded $\mathrm{OH}$ groups is asymmetric. Parallel gravimetric measurements indicate sorption of more than one alkane molecule per SiOHAl group.

Conceptually, the forces causing sorption of the n-alkanes can be split into two contributions, (i) direct hydrogen bonding and (ii) lateral interactions of the rest of the molecule with the zeolite walls. Hydrogen bonding interaction of the Brønsted acidic zeolite $\mathrm{OH}$ group with a $\mathrm{CH}_{2}$ group of the alkane is caused by the electrostatic attraction between the positive charge at the hydroxyl proton and the dipole induced in the alkane $\mathrm{C}-\mathrm{H}$ group. Like with other weak electron pair donor molecules, this leads to a shift of the band of $\mathrm{OH}$ stretching vibration of the zeolite to lower wavenumbers. The magnitude of the shift indicates the strength of the interaction [18]. For a given hydrocarbon the differences in wavenumbers between the free and the perturbed $\mathrm{Si}-\mathrm{OH}-\mathrm{Al}$ group is, at least, for the larger hydrocarbons quite similar and only subtly increases in the sequence HFAU < HMOR. These variations in the shifts are so minor that in a first approximation the strength of the direct interaction of the $\mathrm{Si}-\mathrm{OH}-$ 
$\mathrm{Al}$ and the alkanes can be considered identical for all three zeolites. Characterization by sorption of strong bases also indicates a rather similar acid strength increasing in the sequence H-FAU (heat of ammonia sorption $142 \mathrm{~kJ} / \mathrm{mol}$ ) $<$ H-ZSM5 (heat of ammonia sorption of 147 $\mathrm{kJ} / \mathrm{mol}$ ) < H-MOR (heat of ammonia sorption $151 \mathrm{~kJ} / \mathrm{mol}$ ).

With increasing size of the sorbed alkanes the strength of hydrogen bonding to Brønsted acid sites (monitored via the difference in wavenumbers of perturbed and unperturbed Brønsted acid $\mathrm{OH}$ groups) increases. This indicates that the polarizability of the alkanes increases with increasing size of the molecule, i.e., sorption at the Brønsted acid site induces a stronger dipole the larger the alkane.

In contrast to the strength of the direct hydrogen bonding to the Brønsted acidic $\mathrm{OH}$ groups discussed above, the sorption enthalpy increases with increasing size of the hydrocarbon in the sequence H-FAU < H-MOR < H-ZSM5. In absolute terms, the heat of adsorption of n-alkanes up to heptane was at least 5 to $13 \mathrm{~kJ} / \mathrm{mol}$ higher on H-ZSM5 than on H-MOR and 13 to $29 \mathrm{~kJ} / \mathrm{mol}$ higher than on H-FAU. This suggests that the higher sorption enthalpy with H-ZSM5 is due to stronger interaction of the hydrocarbons with the lattice oxygen atoms (lateral interactions). Sorption measurements on silicalite (i.e., aluminum free HZSM5) show a heat of adsorption which is for each hydrocarbon $10 \mathrm{~kJ} / \mathrm{mol}$ lower than the corresponding heat of adsorption on HZSM5. This clearly indicates the importance of the contributions of the direct (hydrogen bonding) and the lateral interactions. The strength of lateral interactions between the alkanes and the zeolite lattice is speculated to depend on the pore size [172] and/or on the higher polarizability of the lattice. Thus, the polarizable (soft) lattice of HZSM5 enhances the interactions with alkanes being soft bases [170].

The general message of these results is that the direct interactions can be well probed in zeolites by sorption of small bases. The more complex multiple interactions can only be probed by monitoring the influence on the sorbate/reactant itself.

\subsection{Reversible chemisorption at hydroxyl groups on phosphate based molecular sieves}

As outlined above, most pure and mixed oxides including molecular sieves contain hydroxyl groups to terminate the lattice and to equalize charge imbalances. So far we have described means to characterize the concentration and strength of these $\mathrm{OH}$ groups and to differentiate them from Lewis acid sites. Problems concerning high temperature chemisorption of ammonia and amines which result in formation of surface amine groups and the reactivity of nitriles and ketones on the surface of oxides were noted. In none of these cases, however, the chemisorption was reversible within a measurable time scale and the extent of reactivity differed markedly even within similar sorbents varying only in the alkyl substituent.

The most prominent case for such low temperature chemisorption on hydroxyl groups is offered by cloverite. Preliminary results with other metal aluminum phosphates, however, show that such reversible chemisorption on hydroxyl groups is characteristic for metal substituted aluminum phosphates [173]. Cloverite is a large pore gallium phosphate molecular sieve that contains terminal $\mathrm{GaOH}$ and $\mathrm{POH}$ hydroxyl groups protruding into the pores of the molecular sieve. Upon sorption of weak bases like benzene significant red shifts of the bands of the $\mathrm{OH}$ groups occur which suggest that the material is a moderately strong acid [165]. It is important to note that the hydroxyl groups act as Brønsted acids also towards other, more reactive hydrocarbons such as ethylene and that hydrogen bonding is then the main interaction. From these studies, consensus was reached that the strength of the hydrogen bonding was similar to that of $\mathrm{POH}$ groups in macroporous oxides [165].

When ammonia is adsorbed on cloverite 


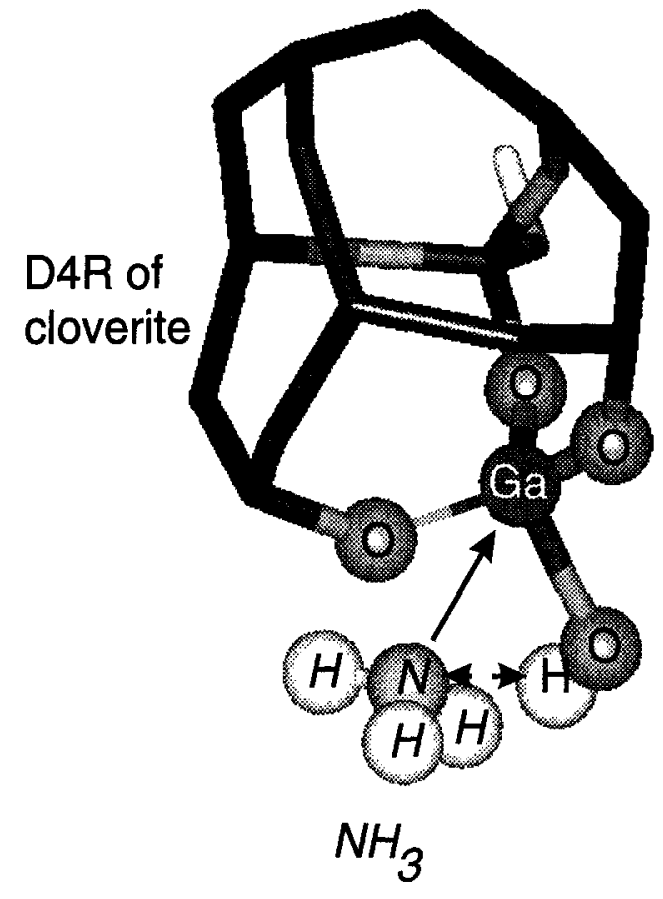

Fig. 8. Proposed adsorption complex of ammonia on cloverite indicating the opening of the $\mathrm{Ga}-\mathrm{O}-\mathrm{P}$ bond

(single crystals) in contrast to the expectations the main sorbed species do not only show IR bands characteristic of ammonium ions, but also those of strongly Lewis bound ammonia. It is concluded that as the $\mathrm{OH}$ bands of cloverite disappear there is simultaneous cleavage of one of the metal oxygen bonds ( $\mathrm{Ga}-\mathrm{O}-\mathrm{P}$ group) or of a metal-OH. The disappearance of the $\mathrm{OH}$ stretching band is primarily ascribed to lateral hydrogen bonding between Lewis acid bound ammonia and the hydroxyl group (Fig. 8). For small bases (water, ammonia) this interaction is irreversible $[33,174]$ and leads to the destruction of the lattice at higher temperatures, but larger bases like pyridine and trimethylamine are sorbed reversibly. The cleavage of the $\mathrm{Me}-\mathrm{OH}$ bond and desorption in the form of water can be ruled out, because of the rapid reappearance of its characteristic band after trimethylamine and pyridine desorption.

The fast opening of the lattice metal-oxygen bond is, however, not confined to nitrogen bases. Other polar molecules like alcohols also show similar adsorption structures and this leads to rather strongly Lewis bound molecules that desorb reactively as formaldehyde [33]. Similar observations have been made also for BeAPO5 [173]. With increasing size of the alcohol the importance of the metal-oxygen bond cleavage decreases [33]. For silica based molecular sieves such reactions seem to be less important, although recently a similar mechanism was proposed by Pelmenshikov et al. [175]. Thus, reactive participation of the metal oxide surface seems to be a more general phenomenon. Its role in catalytic conversions, again, can only be correctly estimated when the reactant molecule or at least a close chemical analogue is used for characterization of the acid properties.

\section{Concluding remarks and outlook}

In summary, it is fair to state that the characterization of acidity of oxides and zeolites is relatively advanced. Many potential probe molecules have been investigated in detail on a wide variety of oxide and zeolite samples. For most of these molecules consensus has been reached with respect to the interpretation of the IR spectra and their role in assessing the acid strength of solid acids. Currently, evaluations of the sorbate-sorptive interactions and the corresponding IR spectra by theoretical (semi-empirical and ab initio) calculations $[73,83]$ are becoming available.

The molecules used for acidity characterizations reviewed here, possess dominating basic properties so that the interaction with the surface involves primarily the direct interaction between the electron pair donor function of the probe molecule and the electron pair acceptor site at the surface. To evaluate the concentration of acid sites, strong and stable bases such as ammonia and pyridine seem to be best suited. With respect to Lewis acid sites, these molecules will also lead to a good differentiation with respect to their strength, usually by monitoring 
shifts of the band of the deformation vibration of the amine base upon sorption. It will not be possible, however, to differentiate the strength of Brønsted acid sites by these means, because these molecules will be easily protonated and their strength of adsorption will then depend crucially on the base strength of the deprotonated solid. Evidence for this was recently given by Kotrla and Kubelkova [120].

If one needs to evaluate the strength (polarizability) of Brønsted acidic hydroxyl groups, molecules with weaker base strength should be used. Such molecules perturb the hydroxyl group sufficiently to induce a shift in the absorption maximum of the $\mathrm{OH}$ stretching vibration band which can be used to scale the acid strength. The most successful molecules used for this purpose are (alkyl substituted) benzene, $\mathrm{CO}$ and, most recently reported, ethene. The perfect fit between the shifts in wavenumbers of the $\mathrm{OH}$ stretching vibration bands observed for ethylene and for $\mathrm{CO}$ (see Fig. 5) suggests that both molecules can be used for probing the vast majority of acid sites. To probe the accessibility of sites for more bulky molecules, e.g., benzene and substituted benzenes may preferably be used. The use of more basic molecules to probe the accessibility is not recommended as the high proton affinity of these molecules might pull out protons from more remote locations. Indications for this were discussed above for the case of pyridine sorption on mordenites.

While the use of IR spectra of sorbed probe molecules allows in general to scale the strength and also the concentration of acid sites of oxides and zeolites, it is not straightforward to use these data to estimate turnover frequencies or to predict from these rankings the catalytic behavior. This is related to the fact that the probe molecule and the reactant interact with the surface of the solid in a different way. IR spectroscopy of sorbed molecules, which are chemically similar to the reactants, is an important tool to understand the physical and chemical properties of a particular catalyst. However, it is strongly recommended to use the reactant molecules themselves (when possible) to probe the acid-base properties of the catalyst, if the acidity scale should reflect their importance for a catalytic reaction. In combination with theoretical calculations, this should enable the assessment of the acidity of solids and, in turn, to provide ways of fine tuning and optimizing their acidic properties for a particular use in catalysis.

\section{Acknowledgements}

J.A.L. acknowledges gratefully the support of the Austrian Fonds zur Förderung der Wissenschaftlichen Forschung, the Christian Doppler Society and NIOK for developing in situ spectroscopic techniques for catalyst characterization. The authors are grateful to Florian Eder, Saskia Feast, and Georg Müller for helpful discussions.

\section{References}

[1] L.H. Little, Infrared Spectra of Adsorbed Species, Academic Press, London, 1966.

[2] M.L. Hair, Infrared Spectroscopy in Surface Chemistry, Marcel Dekker, New York, 1967.

[3] A.V. Kieselev and V.I. Lygin, Infrared Spectra of Surface Compounds, Wiley, New York, 1975.

[4] W.N. Delgass, G.L. Haller, R. Kellermann and J.H. Lunsford, Spectroscopy in Heterogeneous Catalysis, Academic Press, New York, 1979.

[5] R.P. Eischens and W.A. Pliskin, Adv. Catal., 10 (1958) 1.

[6] H. Knözinger, Adv. Catal., 25 (1976) 184.

[7] A.T. Bell, in A.T. Bell and M.L. Hair (Editors), Vibrational Spectroscopies for Adsorbed Species, ACS, Washington, DC, 1980 , p. 13.

[8] G.L. Haller, Catal. Rev.-Sci. Eng., 23 (1981) 477.

[9] C.L. Angell, Fourier Transform Infrared Spectroscopy, Vol. 3, Academic Press, New York, 1982, p. 1.

[10] E.A. Paukshtis and E.N. Yurchenko, Russ. Chem. Rev., 52 (1983) 242.

[11] J.B. Peri, in J.R. Anderson and M.Boudart (Editors), Catalysis, Springer Verlag, Berlin, 1984, Vol. 5, p. 172.

[12] J.B. Peri, in S.A. Bradley, M.J. Gattuso and R.J. Bertolacini (Editors), Characterization and Catalyst Developement, ACS, Washington, DC, 1989, p. 222.

[13] M.G. White, in D.L. Perry (Editor), Applications of Analytical Techniques to the Characterization of Materials, Plenum Press, New York, 1991, p. 169.

[14] H. Knözinger, in R.W. Joyner and R.A. van Santen (Edi- 
tors), Elementary Reaction Steps in Heterogeneous Catalysis, Kluwer, Dordrecht, 1993, p. 267.

[15] J.M. McKay and V.E. Henrich, Phys. Rev. B, 32 (1985) 6764.

[16] A. Zecchina, M.G. Lofthouse and F.S. Stone, J. Chem. Soc., Faraday Trans. I, 71 (1975) 1476.

[17] A. Zecchina and F.S. Stone, J. Chem. Soc., Faraday Trans. I, 72 (1976) 2364.

[18] M.L. Hair and W. Hertl, J. Phys. Chem., 74 (1970) 91.

[19] H. Knözinger, Surf. Sci., 41 (1974) 339.

[20] J.A. Lercher and H. Noller, J. Catal., 77 (1982) 152

[21] R.T. Sanderson, Science, 114 (1951) 670.

[22] R.T. Sanderson, Chemical Bonds and Bond Energy, Academic Press, New York, 1976.

[23] R.G. Pearson, J. Am. Chem. Soc., 85 (1963) 3533.

[24] K. Tanabe, Solid Acids and Bases, Academic Press, New York, 1970.

[25] K. Tanabe, in J.R. Anderson and M. Boudard (Editors), Catalysis-Science and Technology, Vol. 2, Springer Verlag, Berlin, 1981, p. 231.

[26] J.A. Lercher, React. Kin. Catal. Lett., 20 (1982) 409.

[27] J.A. Lercher, Ch. Colombier and H.Noller, Z. Phys. Chem. N.F., 131 (1982) 111.

[28] G.Ritter, H. Noller and J.A. Lercher, J. Chem. Soc., Faraday Trans. I, 78 (1982) 2239.

[29] E.M. Flanigen, Stud. Surf. Sci. Catal., 58 (1991) 13.

[30] R. Szostak, Stud. Surf. Sci. Catal., 58 (1991) 153.

[31] J.W. Ward, J. Catal., 10 (1968) 34.

[32] H.G. Karge, in E.G. Derouane et al. (Editors), Zeolite Micropous Solids: Synthesis, Structure and Reactivity, Kluwer, Dordrecht, 1992, p. 273.

[33] G. Müller, G. Eder-Mirth and J.A. Lercher, J. Phys. Chem., (1995) in press.

[34] P.R. Griffiths and J.A. de Haseth, Fourier Transform Infrared Spectroscopy, Wiley, New York, 1986.

[35] K.W. van Every and P.R. Griffiths, Appl. Spectrosc., 45 (1991) 347.

[36] R.J.Jakobsen, in J.R. Ferraro and L.J. Basile (Editors), Fourier Transform Infrared Spectroscopy Vol. 2, Academic Press, New York, 1979, p. 165.

[37] D.B. Parry and J.M. Harris, Appl. Spectrosc., 6 (1988) 997.

[38] F.M. Hoffmann and M.D. Weisel, in D.J. Dwyer and F.M. Hoffmann (Editors), Surface Science of Catalysis: In Situ Probes and Reaction Kinetics, ACS, Washington, DC, 1992, p. 202.

[39] Y.-H. Pao, Optoacoustic Spectroscopy and Detection, Academic Press, New York, 1977.

[40] J.G. Highfield and J.B. Moffat, J. Catal., 98 (1986) 245.

[41] H.P. Wang, E.M. Eyring and H. Huai, Appl. Spectrosc., 45 (1991) 883 .

[42] M. Nowotny, H. Kessler and J.A.Lercher, Zeolites, 11 (1991) 454.

[43] H. Knözinger, H. Stolz, H. Bühl, G. Clement and W. Meye, Chem. Ing. Technik, 42 (1970) 548.

[44] C.T. O'Connor, J.C.Q. Fletcher and M.W. Rautenbach, J. Phys. E: Sci. Instrum., 19 (1986) 367.

[45] A. Jentys, G. Rumplmayr and J.A. Lercher, Appl. Catal., 53 (1989) 299.
[46] M. Nagai, L.L. Lucietto, Y.-E. Li and R.D. Gonzalez, J. Catal., 101 (1986) 522.

[47] H.G. Karge and W. Niessen, Catal. Today, 8 (1991) 451.

[48] G. Mirth, F. Eder and J.A. Lercher, Appl. Spectrosc., 48 (1994) 194.

[49] F. Schiith, J. Phys. Chem., 96 (1992) 7493.

[50] G. Müller, T.F. Narbeshuber, G. Mirth and J.A. Lercher, J. Phys. Chem., 98 (1994) 7436.

[51] D.J. Parillo, R.J. Gorte and W.E. Farneth, J. Am. Chem. Soc., 115 (1993) 12441.

[52] M. Deeba and W. K. Hall, J. Catal., 60 (1979) 417

[53] G. Mirth and J.A. Lercher, J. Phys. Chem., 95 (1991) 3736.

[54] G. Mirth, J. Cejka and J.A. Lercher, J. Catal., 139 (1993) 24.

[55] W. Niessen and H.G. Karge, Microporous Mater., 1 (1993) 1.

[56] M. Hermann, W. Niessen and H.G. Karge, Stud. Surf. Sci. Catal., 94 (1995) 131.

[57] J.W. Ward, J. Catal., 18 (1970) 348.

[58] J.W. Ward, J. Catal., 9 (1976) 225.

[59] P.A. Jacobs and J.B. Uytterhoeven, J. Chem. Soc., Faraday Trans. I, 69 (1973) 359.

[60] P.A. Jacobs, Catal. Rev.-Sci. Eng., 24 (1982) 415.

[61] P.O. Fritz and J.H. Lunsford, J. Catal., 118 (1989) 85.

[62] J. Datka, M. Boczar and B. Gil, Langmuir, 9 (1993) 2496.

[63] K. Hatada, Y. Ono, and Y. Ushiki, Z. Phys. Chem., 117 (1979) 37.

[64] M.T. Aronson, R.J. Gorte and W.E. Farneth, J. Catal., 105 (1987) 455.

[65] P.A. Jacobs and R. von Ballmoos, J. Phys. Chem., 86 (1982) 3050.

[66] P.A. Jacobs and W.F. Mortier, Zeolites, 2 (1982) 226.

[67] W.J. Mortier, in J.B. Moffat (Editor), Theoretical Aspects of Heterogeneous Catalysis, Van Nostrand Reinold, New York, 1990, p. 135.

[68] V. Gutmann, The Donor-Acceptor Approach to Molecular Interactions, Plenum Press, New York, 1978.

[69] E.H. Teunissen, R.A. van Santen and A.P.J. Jansen, J. Phys. Chem., 97 (1993) 203.

[70] J.A. Lercher, Z. Phys. Chem. N.F., 129 (1982) 209.

[71] J.A. Lercher, H. Vinek and H. Noller, J. Chem. Soc., Faraday Trans. I, 80 (1984) 1239.

[72] E.P. Parry, J. Catal., 2 (1963) 371.

[73] R. A. van Santen and G.J. Kramer, Chem. Rev., 95 (1995) 637.

[74] L.M. Parker, D.M. Bibby and G.R. Burns, Stud. Surf. Sci. Catal., 49 (1988) 963.

[75] A.G. Pelmenschikov, R.A. van Santen, J. Phys. Chem., 97 (1993) 10678.

[76] A.G. Pelmenschikov, G.H.M.C. van Wolput, J. Jänchen and R.A. van Santen, J. Phys. Chem., 99 (1995) 3612.

[77] A. Jentys, G. Warecka, M. Derewinski and J.A. Lercher, J. Phys. Chem., 93 (1989) 4837.

[78] L. Marchese, P.A. Wright and J.M. Thomas, J. Phys. Chem., 97 (1993) 8109.

[79] G. Mirth, J.A. Lercher, M.W. Anderson and J. Klinowski, J. Chem. Soc., Faraday Trans. I, 86 (1990) 3096.

[80] G. Mirth, A. Kogelbauer and J.A. Lercher, in R. von 
Ballmoos (Editor), Proc. 9th IZC, Butterworth-Heinemann, Montreal, 1992, p. 251..

[81] L. Kubelkova, J. Novakova and K. Nedomova, J. Catal., 124 (1990) 441.

[82] L. Kubelkova, J. Ceijka and J. Novakova, Zeolites, 11 (1991) 48.

[83] J. Sauer, P. Ugliengo, E. Garrone and V.R. Saunders, Chem. Rev., 94 (1994) 2095.

[84] P.A. Jacobs, J.A. Martens, J. Weitkamp and H.K. Beyer, Far. Disc. Chem. Soc., 72 (1981) 351.

[85] R.G. Parr and R.G. Pearson, J. Am. Chem. Soc., 105 (1983) 7512.

[86] R.L. Burwell, Jr., J.F. Read, K.C. Taylor and G.L. Haller, Z. Phys. Chem. (Frankfurt am Main), 64 (1969) 18.

[87] R.L. Burwell, Jr., in F. Basalo and R.L. Burwell, Jr. (Editors), Catalysis-Progress in Research, Plenum Press, New York, 1973, p. 51.

[88] N. Cardona-Martinez and J.A. Dumesic, J. Catal., 129 (1991) 23.

[89] C. Mirodatos and D. Barthomeuf, J. Catal., 114 (1988) 121.

[90] J.A. Rabo and G.J. Gajda, in D. Barthomeuf et al.(Editors), Guidelines for Mastering the Properties of Molecular Sieves, Plenum Press, New York, 1990, p. 273.

[91] J.B Peri, J. Phys. Chem., 69 (1956) 211.

[92] P. Fink and J. Datka, J Chem. Soc., Faraday Trans. I, 85 (1989) 309.

[93] L. Volpe and M.Boudart, J. Solid State Chem., 59 (1985) 332.

[94] T. Morimoto, J. Imai and M. Nagao, J. Phys. Chem., 78 (1974) 704

[95] J. Koubek, J. Volf and J. Pasek, J. Catal., 38 (1975) 385.

[96] J. Medema, J.G.M. van Bokhoven and A.E.T. Kuiper, J. Catal., 25 (1972) 238

[97] T.J.G. Kofke, R.J. Gorte and W.E. Farneth, J. Catal., 114 (1988) 34.

[98] D.J. Parillo, A.T. Adamo, G.T. Kokotailo and R.J. Gorte, Appl. Catal., 67 (1990) 107.

[99] T.J.G. Kofke, R.J. Gorte and G.T. Kokotailo, J. Catal., 116 (1989) 252.

[100] C. Peireira and R.J. Gorte, Appl. Catal. A, 90 (1992) 145.

[101] C.H. Kline and J. Turkevich, J. Chem. Phys., 12 (1944) 300.

[102] W. Pohle and P. Fink, Z. Phys. Chem. N.F. 109 (1978) 205.

[103] A. Chambellan, T. Chevreau, S. Khabtou, M. Marzin and J.C. Lavalley, Zeolites, 10 (1992) 306.

[104] S. Khabtou, T. Chevreau and J.C. Lavalley, Microporous Mater., 3 (1995) 133.

[105] H.A. Benesi, J. Catal., 28 (1973) 176.

[106] H. Knözinger and H. Stolz, Ber. Bunsenges. Phys. Chem., 75 (1971) 1055.

[107] H. Knözinger, H. Krietenbrink and P. Ratnasamy, J. Catal., 48 (1977) 436.

[108] J. Kotrla, J. Florian, L. Kubelkova and J. Fraissard, Collect. Czech. Chem. Commun., 60 (1995) 393.

[109] H. Knözinger and H. Krietenbrink, J. Chem. Soc., Faraday Trans. I, 71 (1975) 2421.

[110] A.G. Pelmenschikow, R.A. van Santen, J. Jänchen and E. Meijer, J. Phys. Chem., 97 (1993) 11071.
[111] J. Florian and L. Kubelkova, J. Phys. Chem., 98 (1994) 8734.

[112] L. Kubelkova, J. Kotrla and J. Florian, J. Phys. Chem., 99 (1995) 10285.

[113] J.A. Lercher, H. Noller and G. Ritter, J. Chem. Soc., Faraday Trans. I, 77 (1981) 621.

[114] H. Karge, Surface Sci., 40 (1973) 157.

[115] R.E. Sempels and P.G. Rouxhet, J. Colloid Interf. Sci., 55 (1976) 263.

[116] P.O. Scokart, F.D. Declerck, R.E. Sempels and P.G. Rouxhet, J. Chem. Soc., Faraday Trans. I, 73 (1977) 359.

[117] P.O. Scokart and P.G. Rouxhet, J. Colloid Interf. Sci., 86 (1982) 96

[118] G. Busca, Langmuir, 2 (1986) 577.

[119] M.H. Healy, L.F. Wieserman, E.M. Arnett and K. Wefers, Langmuir, 5 (1989) 114.

[120] J. Kotrla and L. Kubelkova, Stud. Surf. Sci. Catal., 94 (1995) 509.

[121] J. Jänchen, M.J. Haanepen, M.P.J. Peeters, J.H.M.C. van Wolput, J.P. Wolthuizen and J.H.C. van Hooff, Stud. Surf. Sci. Catal., 84 (1994) 373.

[122] J.-C. Lavalley and J. Caillod, J. Chim. Phys., 77 (1980) 373.

[123] C.U. Odenbrand, J.G.M. Brandin and G. Busca, J. Catal, 135 (1992) 505.

[124] A. Jentys and J.A. Lercher, Stud. Surf. Sci. Catal., 46 (1989) 847.

[125] P. Fink, W. Pohle and A. Köhler, Z. Chem., 12 (1972) 117.

[126] Ch. Minchev, V. Kanazirev, V. Mavrodinova, V. Penchev and H. Lechert, Stud. Surf. Sci. Catal., 46 (1989) 29.

[127] C. Halik, J.A. Lercher and H. Mayer, J. Chem. Soc., Faraday Trans. I, 84 (1988) 291.

[128] C. Halik, S. Chaudhuri and J.A. Lercher, J. Chem. Soc., Faraday Trans. I, 85 (1989) 3879.

[129] M. Derewinski, J. Haber, J. Ptaszynski, J.A. Lercher and G. Rumplmayr, Stud. Surf. Sci. Catal., 28 (1986) 957.

[130] G. Eder-Mirth, H.D. Wanzenboeck and J.A. Lercher, Stud. Surf. Sci., 94 (1995) 449.

[131] G. Eder Mirth, Collect. Czech. Chem. Commun., 60 (1995) 421.

[132] N.S. Hush and M.L. Williams, J. Molec. Spectrosc., 50 (1974) 349.

[133] C.L. Angell and P.C. Schaffer, J. Phys. Chem., 70 (1966) 1413.

[134] P.G. Harrison and E.W. Thomton, J. Chem. Soc., Faraday Trans. I, 74 (1978) 2703.

[135] P.G. Harrison and E.W. Thornton, J. Chem. Soc., Faraday Trans. I, 75 (1979) 1487.

[136] R. Larsson, R. Lykvist and B. Rebenstorf, Z. Phys. Chem. (Leipzig), 263 (1982) 1089.

[137] M.I. Zaki and H. Knözinger, Spectrochim. Acta, 43A (1987) 1455.

[138] H. Knözinger, in K. Tanabe, H. Hattori, T. Yamaguchi and T. Tanaka (Editors), Acid-Base Catalysis, Kodansha, Tokyo, and Verlag Chemie, Weinheim, 1989, p. 147.

[139] M.I. Zaki and H. Knözinger, J. Catal., 119 (1989) 311.

[140] D.A. King, J. Electron Spectrosc. Relat. Phenom., 29 (1983) 11. 
[141] B.N.T. Persson and R. Ryberg, Solid State Commun., 36 (1980) 613.

[142] R.I. Soltanov, E.A. Paukshtis and E.N. Yurchenko, Kinet. Catal. (Engl.), 23 (1982) 135.

[143] A.A. Tsyganenko, L.A. Denisenko, S. Zwerev and V.N. Filimonov, J. Catal., 94 (1985) 10.

[144] A. Zecchina, E. Escalona Platero and C. Otero Areán, J. Catal., 107 (1987) 244.

[145] A. Zecchina, S. Coluccia, E. Guglielminotti and G. Ghiotti, J. Phys. Chem., 75 (1971) 2774.

[146] D. Scarano, A. Zecchina and A. Reller, Surf. Sci., 198 (1988) 11.

[147] G. Busca, Langmuir, 2 (1986) 577.

[148] C. Morterra, S. Coluccia, E. Garrone and G. Ghiotti, J. Chem. Soc., Faraday Trans. I, 75 (1979) 289.

[149] G. Della Gatta, B. Fubini, G. Ghiotti and C. Morterra, J. Catal., 43 (1976) 90.

[150] G. Ghiotti, E. Garrone, C. Morterra and F. Boccuzzi, J. Phys. Chem., 83 (1979) 2863.

[151] T.P. Beebe, P. Gelin and J.T. Yates, Surf. Sci., 148 (1984) 526.

[152] H. Knözinger, in K. Tanabe, H. Hattori, T. Yamaguchi and T. Tanaka (Editors), Acid-Base Catalysis, Kodansha, Tokyo, 1989, p. 147.

[153] L. Kubelkova, S. Beran and J. A. Lercher, Zeolites, 9 (1989) 539.

[154] L. Kubelkova and J. Novakova, Zeolites, 11 (1991) 882.

[155] C.L. Angell and M.V. Howell, J. Phys. Chem., 73 (1969) 2551.

[156] G. Busca and V. Lorenzelli, J. Catal., 66 (1980) 155.

[157] J.C. Lavalley, J. Lamotte, G. Busca and V. Lorenzelli, J. Chem. Soc. Chem. Commun., (1985) 1006.

[158] J. Caillod and J.-C. Lavalley, J. Chim. Phys., 77 (1980) 379 .
[159] J. Datka, J. Chem. Soc., Faraday Trans. I, 76 (1980) 705.

[160] J. Datka, J. Chem. Soc., Faraday Trans. I, 77 (1981) 2633.

[161] J. Datka, Zeolites, 11 (1991) 739.

[162] W. Schulz and H. Knözinger, J. Phys. Chem., 80 (1976) 1502.

[163] G.C. Pimentel and A.L. McClellan, The Hydrogen Bond, Freeman, San Francisco, CA, 1960.

[164] J.C. Lavalley, S. Jolly-Feaugas, A. Janin and J. Saussey, Microchim. Acta, in press.

[165] A. Janin, J.C. Lavalley, E. Benazzi, C. Schott-Darie and H. Kessler, Stud. Surf. Sci. Catal., 94 (1995) 124.

[166] M. Derewinski, J. Haber, J. Ptaszynski, J.A. Lercher and G. Rumplmayr, Stud. Surf. Sci. Catal., 28 (1986) 957.

[167] J.A. Lercher, G. Warecka and M. Derewinski, in M.J. Phillips and M.Ternan, Proc. 9th ICC, Calgary, 1988, p. 364.

[168] C. Morterra, A. Chiorino, G. Ghiotti and E. Garrone, J. Chem. Soc., Faraday Trans. I, 75 (1979) 271.

[169] G. Mirth and J.A. Lercher, J. Catal., 132 (1991) 244.

[170] F. Eder, M. Stockenhuber and J.A. Lercher, Stud. Surf. Sci. Catal., 97 (1995) 495.

[171] M. Stockenhuber and J.A. Lercher, Microporous Mater., 3 (1995) 457.

[172] S.B. McCullen, P.T. Reischman and D.H. Olson, Zeolites, 13 (1993) 640.

[173] G. Müller and J.A. Lercher, unpublished results.

[174] J. Patarin, C. Schott, A. Merrouche, H. Kessler, M. Soulard, L. Delmotte, J.L. Guth, J.F. Joly, in R. Von Ballmoos et al. (Editors), Proc. 9th IZC, Butterworth-Heinemann, Montreal, 1993, p. 263.

[175] A.G. Pelmenschikov, G. Morosi, A. Gamba, A. Zecchina, S. Bordiga and E.A. Paukshtis, J. Phys. Chem., in press. 